\title{
Targeted disruption of dual leucine zipper kinase and leucine zipper kinase promotes neuronal survival in a model of diffuse traumatic brain injury
}

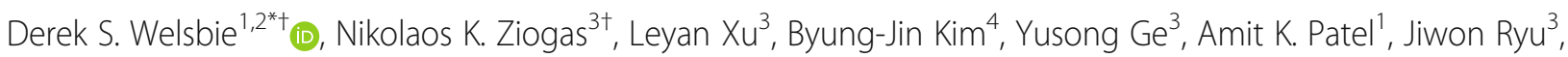
Mohamed Lehar ${ }^{5}$, Athanasios S. Alexandris ${ }^{3}$, Nicholas Stewart ${ }^{3}$, Donald J. Zack ${ }^{4,6,7,8^{*}}$ and Vassilis E. Koliatsos ${\text {, } 3,9^{*}}^{*}$

\begin{abstract}
Background: Traumatic brain injury (TBI) is a major cause of CNS neurodegeneration and has no disease-altering therapies. It is commonly associated with a specific type of biomechanical disruption of the axon called traumatic axonal injury (TAl), which often leads to axonal and sometimes perikaryal degeneration of CNS neurons. We have previously used genome-scale, arrayed RNA interference-based screens in primary mouse retinal ganglion cells (RGCs) to identify a pair of related kinases, dual leucine zipper kinase (DLK) and leucine zipper kinase (LZK) that are key mediators of cell death in response to simple axotomy. Moreover, we showed that DLK and LZK are the major upstream triggers for JUN N-terminal kinase (JNK) signaling following total axonal transection. However, the degree to which DLK/LZK are involved in TAI/TBI is unknown.
\end{abstract}

Methods: Here we used the impact acceleration (IA) model of diffuse TBI, which produces TAl in the visual system, and complementary genetic and pharmacologic approaches to disrupt DLK and LZK, and explored whether DLK and LZK play a role in RGC perikaryal and axonal degeneration in response to TAI.

Results: Our findings show that the IA model activates DLK/JNK/JUN signaling but, in contrast to axotomy, many RGCs are able to recover from the injury and terminate the activation of the pathway. Moreover, while DLK disruption is sufficient to suppress JUN phosphorylation, combined DLK and LZK inhibition is required to prevent RGC cell death. Finally, we show that the FDA-approved protein kinase inhibitor, sunitinib, which has activity against DLK and LZK, is able to produce similar increases in RGC survival.

Conclusion: The mitogen-activated kinase kinase kinases (MAP3Ks), DLK and LZK, participate in cell death signaling of CNS neurons in response to TBI. Moreover, sustained pharmacologic inhibition of DLK is neuroprotective, an effect creating an opportunity to potentially translate these findings to patients with TBI.

Keywords: Traumatic axonal injury, Concussion, Cell death, Traumatic brain injury, Optic neuropathy, Dual leucine zipper kinase, DLK, LZK, Retinal ganglion cell

\footnotetext{
*Correspondence: dwelsbie@ucsd.edu; donzack@gmail.com; koliat@jhmi.edu Derek S. Welsbie and Nikolaos K. Ziogas are Equal first authors

'Department of Ophthalmology, University of California, San Diego, La Jolla 92037, USA

${ }^{4}$ Department of Ophthalmology, The Johns Hopkins University School of Medicine, Baltimore, MD 21205, USA

${ }^{2}$ Department of Neurology, The Johns Hopkins University School of

Medicine, Baltimore, MD 21205, USA

Full list of author information is available at the end of the article
}

(c) The Author(s). 2019 Open Access This article is distributed under the terms of the Creative Commons Attribution 4.0 International License (http://creativecommons.org/licenses/by/4.0/), which permits unrestricted use, distribution, and reproduction in any medium, provided you give appropriate credit to the original author(s) and the source, provide a link to the Creative Commons license, and indicate if changes were made. The Creative Commons Public Domain Dedication waiver (http://creativecommons.org/publicdomain/zero/1.0/) applies to the data made available in this article, unless otherwise stated. 


\section{Background}

Traumatic brain injury (TBI) affects over 2.5 million people each year in the U.S. alone, and is associated with lasting deficits in motor, sensory, and higher CNS functions [1]. As of yet, there are no therapies that prevent or alter the course of these conditions and, thus, there is an urgent need to better understand the molecular pathways that are responsible for the underlying neuropathology and then develop disease-modifying drugs. A very common pathology in TBI of various causes and degrees of severity is diffuse or traumatic axonal injury (TAI) [2-6]. TAI is thought to be caused by rotational acceleration of the head resulting in extremely rapid axonal stretching in multiple white matter foci in the forebrain and brain stem. We and others have shown that TAI can be modeled in the rodent brain with specifically arranged impact forces [7-12].

A consistent finding in multiple TBI models, including blunt force models such as fluid percussion and impact acceleration (IA) as well as blast, is the presence of TAI in the optic nerve and optic tract [11, 13-15]. This interesting observation, combined with the accessibility and compartmentalized anatomy of the visual system, suggests that retinal ganglion cells (RGCs) are an excellent neuronal system in which to model TAI and explore the underlying cellular and molecular mechanisms.

We have previously identified the key mediators involved in RGC axon injury signaling in primary mouse RGCs with a high-throughput, functional genomic screen. Using small interfering RNAs (siRNAs) to knockdown gene expression, we screened through the mouse genome and, along with others, identified a multi-tiered kinase cascade that is responsible for axon injury signaling in vitro and in vivo [16-19]. This cascade includes the mitogenactivated protein kinase kinase kinases (MAP3Ks) dual leucine zipper kinase (DLK/MAP3K12) and leucine zipper kinase (LZK/MAP3K13), the mitogen-activated protein kinase kinases (MAP2Ks) MKK4/MAP2K4 and MKK7/ MAP2K7, and the mitogen-activated protein kinases (MAPKs) JUN N-terminal kinase (JNK) 1-3. In response to optic nerve crush (ONC), DLK is robustly upregulated at the site of axonal injury and is transported to the soma where it initiates a toxic genetic program mediated by multiple transcription factors including JUN [16, 17, 20, 21]. While DLK inhibition is sufficient to reduce cell death after axonal injury, combined DLK and LZK inhibition leads to a more robust protective phenotype suggesting some degree of redundancy [18]. Moreover, there is still uncertainty as to the degree of participation of DLK in the degeneration of axons following injury [16, 17, 22-24]. To the extent that TAI in various models of TBI, including IA, engages this same injury signaling cascade, DLK/LZK inhibition could become part of a neuroprotective treatment strategy for TBI.
In the present study, we explore the activation of DLK/LZK signaling in RGCs in the course of TAI in the mouse visual system inflicted with IA. We then establish the role of this kinase pathway in RGC somal and axonal degeneration with genetic and pharmacological strategies designed to block DLK and LZK. Our results indicate that the DLK/LZK-JNK axis is robustly involved in RGC death associated with TAI in the visual system and suggest a broader role of this kinase cascade in primary axonopathies associated with TBI.

\section{Methods}

\section{Experimental subjects and IA procedures}

Eight-week-old male C57BL/6 J wild-type mice and transgenic $D l k^{f l / f l}$ and $D l k^{f l / f l} L z k^{f l f l}$ mice were subjected to IA or sham injury. Male mice were chosen such as to avoid the confounding effects of sex hormones on injury outcomes [25-29]. Wild-type mice and founders were purchased from Charles River Laboratories (Wilmington, MA). Animals were housed in a vivarium with a 12-h light/12-h dark cycle and given ad libitum access to food and water. All animal handling as well as surgical and postoperative procedures were carried out according to protocols approved by the Animal Care and Use Committee of the Johns Hopkins Medical Institutions.

Impact acceleration injury was performed with heightweight settings generating kinetic energy of $0.45-0.5 \mathrm{~J}$ upon impact, essentially as described $[11,12]$ (Table 1). Immediately prior to injury, the cranium was exposed and a $5 \mathrm{~mm}$-thick stainless-steel disc was glued onto the skull midway between bregma and lambda sutures. Surgical procedures and injury were performed under aseptic conditions with gas anesthesia (isoflurane: oxygen: nitrous oxide $=1: 33: 66$ ). Immediately after injury the disc was removed the skull was checked under the surgical microscope for skull fractures. The rare animals with skull fractures were excluded from further study because such events introduce injuries variables that cannot be easily controlled. Sham animals were subjected to the same procedures, but without the weight drop. The scalp incision was closed with surgical staples, and the animal was returned to cage.

\section{Histology, histochemistry, immunohistochemistry and microscopy}

At the various survival times listed in Table 1, animals were transcardially perfused with freshly depolymerized, $4 \%$ neutral-buffered paraformaldehyde. Eyes were enucleated and fixed for $2 \mathrm{~h}$ while optic nerves were immersed in the same fixative overnight at $4{ }^{\circ} \mathrm{C}$. In some cases, brains were also included in the study for the analysis of optic tracts and superior colliculi. Tissues were cryoprotected in $30 \%$ sucrose and stored at $-80{ }^{\circ} \mathrm{C}$ until further processing. Sagittal brain sections $(40 \mu \mathrm{m})$, some 
Table 1 Impact acceleration condition and survival time for each experimental group

\begin{tabular}{|c|c|c|}
\hline Experiments/groups & Experimental history, survival times post-IA & Procedures \\
\hline 1.Characterization of initial injury in the optic nerve - general & $\begin{array}{l}\text { Sham }(n=3), 4 \mathrm{~h} \text { post-IA }(n=3), 24 \mathrm{~h} \\
\text { post-IA }(n=3) \\
\text { IA:40 } \mathrm{g} \times 1 \mathrm{~m} \text { or } 60 \mathrm{~g} \times 0.85 \mathrm{~m}\end{array}$ & IHC for APP (TAl) and lgG (BBB disruption) \\
\hline $\begin{array}{l}\text { 2. Characterization of initial injury in the optic nerve } \\
\text { - CLARITY }\end{array}$ & $\begin{array}{l}\text { CTB injection immediately post-IA, survival } \\
2 \mathrm{~d} \text { post-IA }(n=3) \\
\text { IA: } 40 \mathrm{~g} \times 1 \mathrm{~m}--60 \mathrm{~g} \times 0.85 \mathrm{~m}\end{array}$ & CLARITY \\
\hline $\begin{array}{l}\text { 3. Characterization of traumatic axonopathy - general } \\
\text { neuropathology in the optic nerve and tract }\end{array}$ & $\begin{array}{l}7 \mathrm{~d} \text { post-IA }(n=3) \\
\text { IA:40 } \mathrm{g} \times 1 \mathrm{~m} \text { or } 60 \mathrm{~g} \times 0.85 \mathrm{~m}\end{array}$ & $\begin{array}{l}\text { Gallyas silver } \\
\text { IHC for neuroinflammation (IBA1) }\end{array}$ \\
\hline $\begin{array}{l}\text { 4. Characterization of traumatic axonopathy - death of RGCs } \\
\text { in retina }\end{array}$ & $\begin{array}{l}\text { Sham }(n=6), 2 \text { wk. post-IA }(n=7), 4 \text { wk. } \\
\text { post-IA }(n=5) \\
\text { IA: } 40 \mathrm{~g} \times 1 \mathrm{~m}\end{array}$ & $\begin{array}{l}\mathrm{IHC} \text { for } \gamma \text { Synuclein } \\
\text { Cell counts on retinal wholemounts }\end{array}$ \\
\hline $\begin{array}{l}\text { 5. Characterization of traumatic axonopathy - axonal } \\
\text { degeneration in optic nerve }\end{array}$ & $\begin{array}{l}\text { Sham }(n=6), 2 \text { wk. post-IA }(n=7), 4 \text { wk. } \\
\text { post-IA }(n=5) \\
\text { IA: } 40 \mathrm{~g} \times 1 \mathrm{~m}\end{array}$ & $\begin{array}{l}\text { Embedding of optic nerve tissues in } \\
\text { epoxy resin, semithin sectioning, toluidine } \\
\text { blue staining }\end{array}$ \\
\hline 6. Induction of DLK-JNK pathway in RGCs after injury & $\begin{array}{l}24 \mathrm{~h}(n=3), 3 \mathrm{~d} \text { post-IA }(n=3) \\
\text { IA:40 } \mathrm{g} \times 1 \mathrm{~m}\end{array}$ & IHC for DLK, p-JUN in retinal sections \\
\hline 7. Time course of DLK-JNK induction in RGCs after injury & $\begin{array}{l}\text { Sham }(n=4), 24 \mathrm{~h} \text { post-IA }(n=10), 3 \mathrm{~d} \\
\text { post-IA }(n=5), 7 \mathrm{~d} \text { post-IA }(n=4), 14 \mathrm{~d} \\
\text { post-IA }(n=3) \\
\text { IA:40 } \mathrm{g} \times 1 \mathrm{~m}\end{array}$ & $\begin{array}{l}\text { IHC for } \gamma \text { Synuclein and } p-J U N \\
\text { Cell counts on retinal wholemounts }\end{array}$ \\
\hline $\begin{array}{l}\text { 8. Time course of activation of distinct member of DLK-JNK } \\
\text { pathway in RGCs after injury }\end{array}$ & $\begin{array}{l}\text { Sham }(n=3), 24 \text { h post-IA }(n=3), 3 \mathrm{~d} \\
\text { post-IA }(n=3), 7 \mathrm{~d} \text { post-IA }(n=3) \\
\text { IA:40 } \mathrm{g} \times 1 \mathrm{~m}\end{array}$ & Standard Western blotting \\
\hline \multirow[t]{2}{*}{$\begin{array}{l}\text { 9. Interventional studies - genetic deletion of DIk on D/kflfll } \\
\text { mice and effects on DLK-JNK pathway activation and RGC } \\
\text { survival }\end{array}$} & $\begin{array}{l}\text { AAV2-Cre-GFP into one eye } \\
\text { AAV2-GFP into fellow eye } \\
(n=4 \text { each, injections } 2 \mathrm{wk} \text {. pre-IA, eu- } \\
\text { thanasia } 3 \text { days post-IA) } \\
\text { IA: } 60 \mathrm{~g} \times 0.85 \mathrm{~m}\end{array}$ & $\begin{array}{l}\text { IHC for } \mathrm{p}-J U N \\
\text { Cell counts on retinal wholemounts }\end{array}$ \\
\hline & $\begin{array}{l}\text { AAV2-Cre-GFP into one eye } \\
\text { AAV2-GFP into fellow eye } \\
(n=7 \text { each, injections } 2 \mathrm{wk} \text {. pre-IA, eu- } \\
\text { thanasia } 4 \mathrm{wk} \text {. post-IA) } \\
\text { IA:60 } \mathrm{g} \times 0.85 \mathrm{~m}\end{array}$ & $\begin{array}{l}\text { IHC for RBPMS } \\
\text { Cell counts on retinal wholemounts }\end{array}$ \\
\hline \multirow[t]{2}{*}{$\begin{array}{l}\text { 10. Interventional studies - genetic deletion of Dlk and Lzk } \\
\text { on DI/ } k^{f / f l} L z k^{f / f f l} \text { and effects on DLK-JNK pathway activation } \\
\text { and RGC survival }\end{array}$} & $\begin{array}{l}\text { AAV2-Cre-GFP into one eye } \\
\text { AAV2-GFP into fellow eye } \\
(n=4 \text { each, injections } 2 \mathrm{wk} \text {. pre-IA, eu- } \\
\text { thanasia } 3 \text { day post-IA) } \\
\text { IA: } 60 \mathrm{~g} \times 0.85 \mathrm{~m}\end{array}$ & $\begin{array}{l}\text { IHC for p-JUN } \\
\text { Cell counts on retinal wholemounts }\end{array}$ \\
\hline & $\begin{array}{l}\text { AAV2-Cre-GFP into one eye } \\
\text { AAV2-GFP into fellow eye } \\
(n=7 \text { each, injections } 2 \text { wk. pre-IA, eu- } \\
\text { thanasia } 4 \text { wk. post-IA) } \\
\text { IA: } 60 \mathrm{~g} \times 0.85 \mathrm{~m}\end{array}$ & $\begin{array}{l}\text { IHC for RBPMS } \\
\text { Cell counts on retinal wholemounts }\end{array}$ \\
\hline $\begin{array}{l}\text { 11. Interventional studies - pharmacologic kinase inhibition } \\
\text { with sunitinib and effects on DLK-JNK pathway activation } \\
\text { and RGC survival }\end{array}$ & $\begin{array}{l}\text { Drug }(n=12) \\
\text { Vehicle }(n=14) \\
\text { both groups } 3 \text { wk. post-IA } \\
\text { IA:40 } \mathrm{g} \times 1 \mathrm{~m}\end{array}$ & $\begin{array}{l}\mathrm{IHC} \text { for } \gamma \text { Synuclein } \\
\text { Cell counts on retinal wholemounts }\end{array}$ \\
\hline
\end{tabular}

with attached distal nerves, were prepared in series for Gallyas silver staining for injured/degenerating axons and terminals and immunohistochemistry (IHC) for the microglial marker IBA1. Gallyas silver staining was performed as described [14]. Sagittal retinal sections $(10 \mu \mathrm{m})$ were prepared on a cryostat and processed in series for immunoperoxidase-based IHC to assay for select members of the DLK-JNK pathway, including DLK, phosphorylated JNK (p-JNK) and phosphorylated JUN (p-JUN). Sagittal sections of the entire optic nerve were used to assay for the presence of axon injury and blood brain barrier (BBB) disruption at early time points post-injury, with amyloid precursor protein (APP) and IgG staining, as described [11]. Retinal flat mounts were prepared as described [11] and used to explore injury responses or survival of RGCs based on p-JUN and $\gamma$-synuclein (SNCG) immunofluorescence. 
In all experiments involving IHC, sections were first incubated in the primary antibody overnight at $4{ }^{\circ} \mathrm{C}$. For immunoperoxidase staining, after incubation with biotinylated secondary antibody (1:200; Jackson ImmunoResearch, West Grove, PA) and then avidin and biotinylated peroxidase, sections were developed with 3 , 3'-diaminobenzidine (DAB) (Vectastain Elite ABC Kit; Vector Laboratories Inc., Burlingame, CA). For immunofluorescence, after incubation in secondary antibodies conjugated with Cy3 or Cy2 (1:200; Jackson ImmunoResearch, West Grove, PA) for $2-4 \mathrm{~h}$ at room temperature, sections were counterstained with the fluorescent DNA dye 4', 6-diamidino-2-phenylindole (DAPI) and coverslipped with DPX. Primary antibodies included: antiIBA1 (1:500; Dako; 019-19,741, Carpinteria, CA or Biocare Medical; CP-290A, Pacheco, CA); DLK (1:200, GeneTex; GTX124127, Irvine, CA); p-JNK (1:200, Cell Signaling Technology; 9251 or 4671, Danvers, MA); pJUN (1:200, Cell Signaling Technology; 9261 or 3270, Danvers, MA); SNCG (1:600; Abnova; H00006623-M01, Walnut, CA or Genetex; GTX110483, Irvine, CA); RBPMS (1:1000, PhosphoSolutions; 1832-RBPMS or 1830-RBPMS, Aurora, CO); and TUJ1 (1:600, Covance; MMS-435P or PRB-435P, Indianapolis, IN or Abcam; ab18207, Cambridge, MA). Immunostained sections were studied on a Zeiss Axiophot microscope equipped for epifluorescence or a Zeiss LSM 510 inverted confocal microscope. Adobe Photoshop 9.0 software (Adobe Systems, San Jose, CA) was used for image processing.

\section{CLARITY-based processing of the optic nerve}

To explore the location and extent of axonal injury in the optic nerve after IA, the anterograde tracer cholera toxin subunit B (CTB) conjugated with Alexa Fluor 488 (CTB 488) was injected intravitreally $1 \mathrm{~h}$ after IA or sham injury. Optic nerves were then dissected and processed by CLARITY as described [12]. In brief, optic nerves were incubated in a hydrogel containing $2 \%$ acrylamide, $0.025 \%$ bisacrylamide, $0.25 \%$ VA-044 initiator and $4 \%$ PFA in $0.1 \mathrm{M}$ PBS overnight $\left(4^{\circ} \mathrm{C}\right)$. After degassing, samples were incubated in a water bath $\left(37^{\circ} \mathrm{C}\right)$ for $3 \mathrm{~h}$. Polymerized nerves were then transferred to a boric acid solution with $4 \%$ SDS and were incubated for 4 days. Prior to imaging, optic nerves were incubated in FocusClear (CellExplorer catalog \#FC-101) and mounted for imaging. Transparent optic nerves were imaged with confocal microscopy at $20 \times$ on a Zeiss AxioExaminer microscope with a 710NLO module (Carl Zeiss Inc., Oberkochen, Germany) and images were visualized with Imaris software (Bitplane, Concord, MA).

\section{Semithin-section processing of the optic nerve}

Optic nerves from sham- and IA-injured subjects were dissected away from the eyes and brains and treated with a solution containing $4 \%$ paraformaldehyde and $0.2 \%$ glutaraldehyde for $24 \mathrm{~h}$. After rinsing in $0.1 \mathrm{M}$ phosphate buffer $(\mathrm{pH} 7.3)$ for 3-10 min, tissues were immersed in $1 \%$ osmium tetroxide for $15 \mathrm{~min}$ and stained en bloc with $1 \%$ uranyl acetate for $1 \mathrm{~h}$. Stained tissues were dehydrated in graded concentrations of ethanol, embedded in Poly/ Bed 812 (Polysciences Inc., Warrington, PA) in $\mathrm{BEEM}^{\circ}$ capsules and polymerized at $60^{\circ} \mathrm{C}$ for $72 \mathrm{~h}$. Semithin sections $(1 \mu \mathrm{m})$ were cut transversely from segments of optic nerves caudal to the eyeball and stained with $1 \%$ toluidine blue. Myelinated axonal profiles were studied under $100 \times$ magnification on a Zeiss Axiophot microscope equipped for epifluorescence (Diagnostic Instruments Inc., Sterling Heights, MI); normal profiles were counted by investigators blinded to experimental history using the optical fractionator probe in the Stereo Investigator ${ }^{\bullet}$ software (Microbrightfield Inc., Williston, VT).

\section{Immunoblots}

To explore the involvement of select members of the DLKJNK axis in visual TAI after IA, we harvested fresh eyeballs at days 1, 3 and 7 after injury and then dissected the retinas and stored them at $-80^{\circ} \mathrm{C}$. For protein extraction, retinas were sonicated in cell lysis buffer containing $1 \mathrm{mM}$ PMSF (Cell Signaling Technology, Danvers, MA), complete protease inhibitor cocktail and PhosSTOP phosphatase inhibitor cocktail (Roche, Basel, Switzerland) and then incubated for $30 \mathrm{~min}$ at room temperature. Solubilized proteins in Laemmli sample buffer were separated on SDS-PAGE gel and then transferred to polyvinylidene fluoride (PVDF) membranes using XCell II blot system (Invitrogen, Carlsbad, CA). Membranes were blocked with 5\% Bovine Serum Albumin (BSA) in Trisbuffered saline $/ 0.05 \%$ Tween- 20 and sequentially incubated in primary antibodies (overnight, $4{ }^{\circ} \mathrm{C}$ ). In addition to DLK, pJNK and p-JUN (all at 1:1000) antibodies that were the same as in previous section, we also used antibodies against phosphorylated MKK4 and MKK7 (1:1000, Cell Signaling Technology, Danvers, MA), and a $\beta$-actin antibody (1:1000, Cell Signaling Technology, Danvers, MA). HRP-conjugated secondary antibody ( $1 \mathrm{~h}$ at RT) and SuperSignal Chemiluminescent Substrate (Thermo Scientific. Reckford, IL) was used to detect protein signals. Image J (National Institutes of Health) and Prism (GraphPad Software, Inc., La Jolla, CA) were used for quantitation and statistical analysis.

\section{$D / k / L z k$ knockout in $D / k^{f l / f l}$ and $D / k^{f l / f l} L z k^{f l / f l}$ mice} Male $D l k^{f l f l}$ and $D l k^{f l f l} L z k^{f l f f l}$ mice were subjected to IA as described above [11, 12]. Two weeks prior to injury, subjects were intravitreally injected in one eye with AAV2 expressing Cre-GFP (AAV-Cre) and in the fellow eye with AAV2 expressing GFP (AAVGFP). In one set of experiments $\left(n=5\right.$ per $D l k^{f l f l}$, $D l k^{f l f l} L z k^{f l f}$ and wild-type mice), 3 days after injury, 
retinal flat mounts were immunostained for p-JUN and taken for counts of immunoreactive neurons as laid out in previous sections, with the AAV2-GFPinjected eye serving as control. In another experimental scenario $\left(n=9-10\right.$ per $D l k^{f l / f l}, D l k^{f l / f l} L z k^{f l / f l}$ and wild-type mice) animals were allowed to survive for 3 weeks and retinal flat mounts were processed for counts of SNCG-positive or RBPMS-positive RGCs as described in previous Sections.

\section{DLK-JNK inhibition with the protein kinase inhibitor} sunitinib

Sunitinib stock solution was made by dissolving drug powder in dimethylsulfoxide (DMSO) at a concentration of $120 \mathrm{mg} / \mathrm{ml}$ and was stored at $-20^{\circ} \mathrm{C}$. At the time of drug administration, stock solution was diluted with saline to a final concentration of $6 \mathrm{mg} / \mathrm{ml}$ and injected intraperitoneally into mice $(60 \mathrm{mg} / \mathrm{kg})$. Sunitinib was administered 24 and $4 \mathrm{~h}$ prior to injury, and then once


Fig. 1 Location of the initial optic nerve disruption injury in IA-injured animals. a-c. Early axonal and BBB changes as shown with double immunofluorescence for APP (green) and mouse lgG (red). Eyeball is to the left, optic chiasm to the right of panel. Four hours after injury, there are multiple axonal swellings and bulbs (green), evidence of primary TAl at approximately 2/3 of optic nerve from the eyeball. There is also disruption of BBB manifested by lgG leakage (red) in the same area but covering a larger segment of the nerve. There are no APP (+) axonal abnormalities or BBB disruption in the optic nerve of sham mice. Insets show representative lesions in two magnifications at four (b) and 24 (c) hours post-injury. $\mathbf{d}$. Disruption of CTB transport in optic nerve after IA injury: Axonal transport in optic nerve was explored by intravitreally injecting CTB488 $1 \mathrm{~h}$ after injury. Processed with CLARITY 2 days after injury, CTB-488 (green) transport is interrupted at approximately $2 / 3$ of the optic nerve from the eyeball at exactly the same site as APP (+) axonal abnormalities and BBB alterations in a-c. e-f. Details of axonal abnormalities at the level of initial mechanical nerve disruption. Panels are magnifications of identically labeled regions in $\mathbf{b}$, $\mathbf{c}$, and $\mathbf{d}$. Note classical axonal bulbs $4 \mathrm{~h}$ post-injury (e), varicosities and undulations at $24 \mathrm{~h}(\mathbf{f})$, and the interrupted axonal transport of CTB in most axons in (g). Scale bars: a-c, $500 \mu \mathrm{m} ; \mathbf{d}, 550 \mu \mathrm{m} ; \mathbf{e}-\mathbf{g}, 50 \mu \mathrm{m}$ 
more immediately after the injury (for the evaluation of p-JUN expression in RGCs) or daily for 3 weeks starting immediately after the injury (for the evaluation of RGC survival). Control animals received injections of vehicle solution.

\section{RGC counts in retinal flatmounts}

The four quadrants of retinal mounts immunolabeled with SNCG and p-JUN were separately imaged with a $20 \times$ objective (0.4 numerical aperture) on a Zeiss LSM 510 inverted confocal microscope (Carl Zeiss Inc., Oberkochen, Germany). Images were adjusted for optimal contrast and brightness with Adobe Photoshop 7.0 and Image J was used to count surviving SNCG (+), RBPMS $(+)$ or injured p-JUN $(+)$ RGCs. Cells were counted in $150 \times 150 \mu \mathrm{m}$ fields from three concentric zones of the same width, from the center to the periphery of the retina, using at least 8 fields per each zone. Cell density was calculated by dividing cell numbers by total area surveyed. The ratio of p-JUN (+) RGCs cells was calculated by dividing the number of p-JUN/SNCG double-labeled cells by the total number of SNCG $(+)$ cells. In a number of experiments, i.e. p-JUN response and survival of RGCs in $D l k^{f l f l}$ and $D l k^{f l f l} L z k^{f l f l}$ mice and RGC survival in the sunitinib
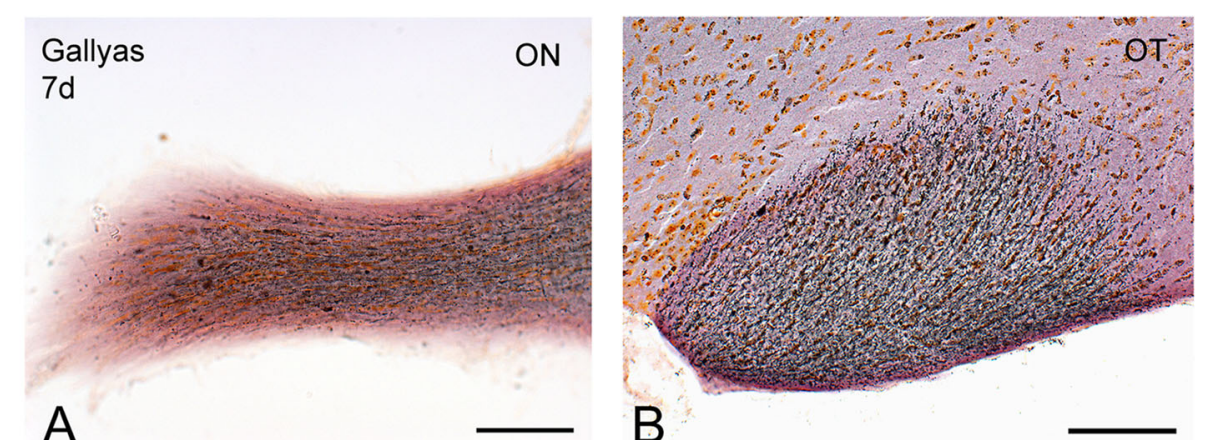

A

B
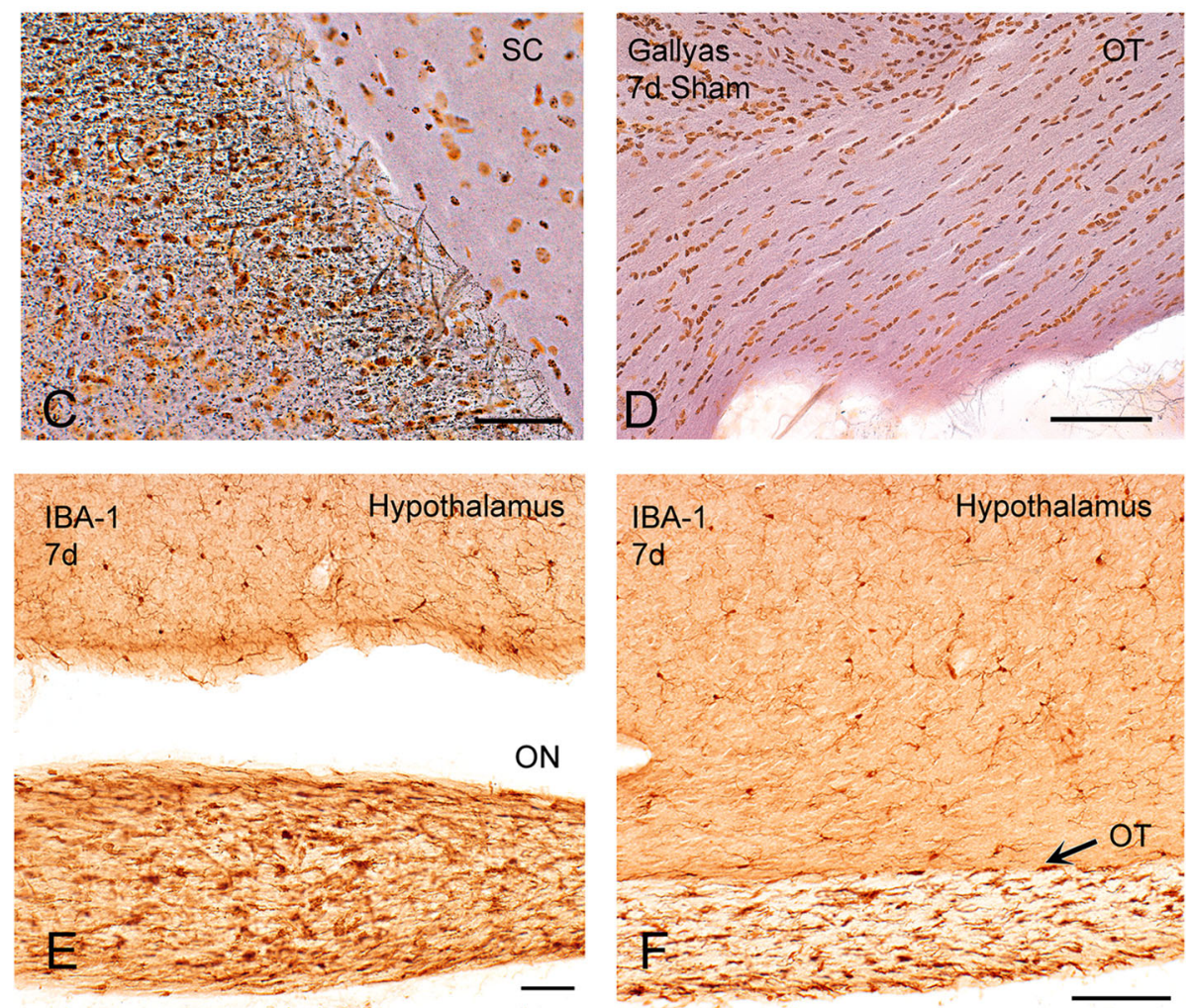

Fig. 2 Axonal degeneration (Gallyas silver) and neuroinflammation in the visual system after IA injury. a-d. Gallyas silver degeneration staining shows axonal pathology (black swellings, lines, trails, dots) 7 days after injury in the optic nerve (ON, a), optic tract (OT, b), and superior colliculus (SC, c). Sham tissues show no silver signal at the same time point (d). e-f. Neuroinflammatory responses are evident by the presence of hypertrophic IBA1 (+) microglia and microglial nodules in these sections prepared 7 days after injury. Note the striking selectivity of neuroinflammation in the visual system (optic nerve [ON] and optic tract [OT]) by comparing IBA1 (+) profiles in ON and OT to normal resting microglia in overlying hypothalamus. Scale bars: a-d, $100 \mu \mathrm{m} ; \mathbf{e}, 80 \mu \mathrm{m} ; \mathbf{f}, 150 \mu \mathrm{m}$ 

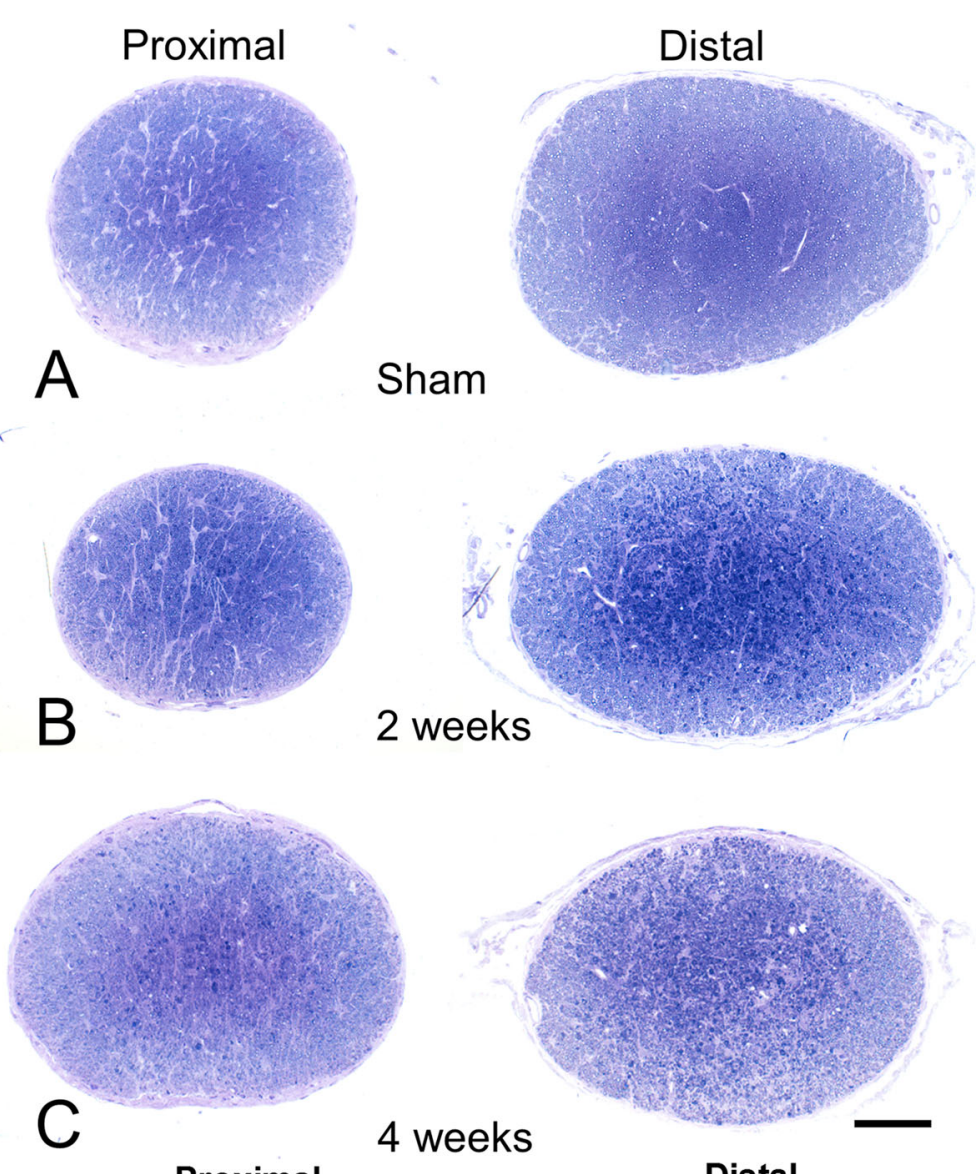

Proximal
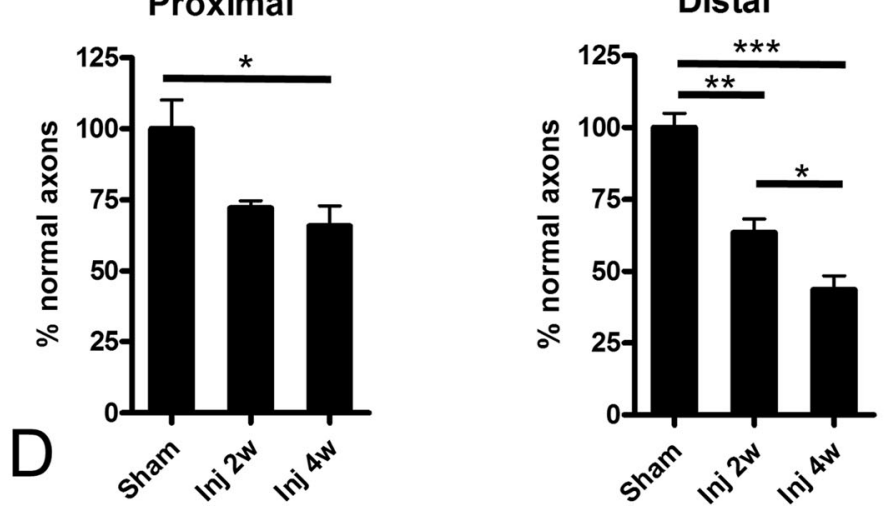

Fig. 3 Axonal degeneration in the proximal and distal optic nerve following IA injury. Axonal pathology in the optic nerve of mice was examined with toluidine blue staining of semithin sections from sham (a) and 2- or 4-week post-injury cases (b and $\mathbf{c}$, respectively). The nerve segment proximal to initial traumatic disruption is on the left, distal to disruption segment (close to chiasm) is on the right. Within the first month, there is evident axonopathy, distal more than proximal. In both segments and time points, pathology is more severe at the center of the nerve. Fields are further enlarged for greater cellular detail in Fig. 4. Panel $\mathbf{d}$ is a bar graph with stereological counts of normal axons in the proximal and distal segments of the optic nerve in the sham condition and at 2 and 4 weeks post injury. Numbers are expressed as percentages of sham because there is a difference in baseline myelinated axons in the proximal and distal segments in this experiment where proximal sections were taken from a plane $\sim 0.5-1 \mathrm{~mm}$ posterior to the eye. Scale bars: $100 \mu \mathrm{m}$

experiment, counts were done using an automated image analysis system (ImageXpress high content imager, Molecular Devices, Sunnyvale CA) using the autofocus and auto-tiling function at $20 \times$ magnification followed by automatic quantification with ImageJ.

\section{Statistical methodologies}

Statistical analysis was carried out with one-way ANOVA or $t$ test. In the case of ANOVA, significant differences were further analyzed with Tukey's post hoc test to reveal important main effects or interactions. For 
counts of axonal number in the characterization of optic neuropathy, numbers were normalized to sham mean. Calculations were performed using Prism 4 (GraphPad Software). Differences were considered significant at $p<0.05$.

\section{Results}

Traumatic axonal injury in the visual system is associated with RGC axonopathy and axonal degeneration

To characterize the initial effect of IA on the optic nerve, sections were immunostained for amyloid precursor protein (APP), a marker of early TAI. As early as $4 \mathrm{~h}$ after injury, we found a distinct region of APP-positive swellings and bulbs between the orbital apex and the chiasm (Fig. 1a-c). Amyloid precursor protein colocalized with IgG immunoreactivity, indicating serum extravasation and blood-brain barrier (BBB) disruption (Fig. 1b-c). Axonal abnormalities included classical axon bulbs and varicosities (Fig. 1e-f). When retinas were injected with CTB488 and optic nerves processed with CLARITY to visualize transport in the nerve, we identified CTB488 transport blockade in the same location of the nerve that had APPpositive axonal abnormalities (Fig. 1d, g). These findings indicate that IA produces a focal traumatic injury to RGC axons in the intracranial portion of the optic nerve.

Seven days after injury, Gallyas silver staining revealed extensive axonal degeneration, from the optic nerve and tract to the superior colliculus (Fig. 2a-d). Degeneration was associated with the presence of deramified/hypertrophic microglia (Fig. 2e-f). Semithin sections of the optic nerve revealed numerous degenerative ovoids and axonal loss at 2 weeks post-injury that was maintained at 4 weeks (Figs. 3 and 4). Axonal degeneration profiles differ between the proximal part of the nerve, close to the eye, with the distal part of the nerve, close to the chiasm. The distal nerve has more pronounced dysmyelination and more severe axonal loss compared to proximal both at two- and four-weeks post injury. There is ongoing degeneration in the distal segment between two- and four-weeks post injury (Fig. 3d). At 4 weeks, de- and dys-myelination were less evident distally, but there was extensive myelin debris (Fig. 4c). To determine if IA caused RGC death, we counted the number of SNCG-positive cells in retinal flatmounts two- and fourweeks post-injury and we found a progressive decrease in the number of RGC somas in the course of the first month (Fig. 5). Taken together, these results suggest that the IA model produces a focal axonal injury that leads to progressive axonal and somal RGC degeneration.

\section{The DLK-JNK pathway is activated in RGCs in the course of visual TAI}

Based on previous work implicating DLK-JNK signaling in RGC degeneration after optic nerve crush, we tested

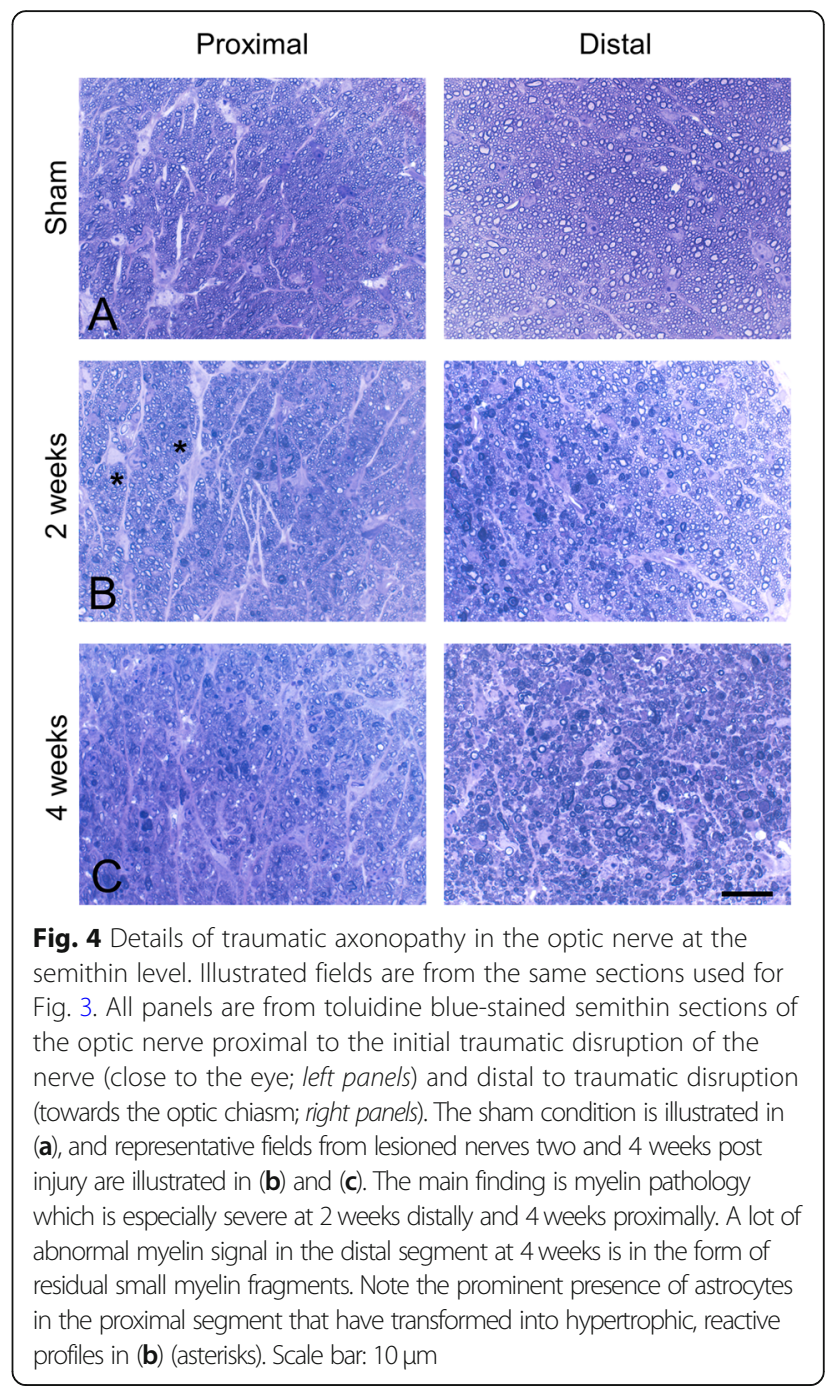

whether a diffuse TBI model such as IA activates the DLK-JNK cascade in a similar fashion. Since DLK levels are indicative of pathway activation, we immunostained retinal sections for DLK and also immunoblotted whole retinal lysates. Both approaches showed transient upregulation of DLK, peaking around 1 day after injury (Fig. 6a, c, e and Fig. 7). We did not pursue LZK IHC or immunoblotting because of the lack of reliable antibodies. To determine if this upregulation was associated with pathway activation, we used immunoblotting and IHC to measure the phosphorylation state of the downstream kinases MKK4, MKK7, JNK1-3, and the transcription factor JUN. By 1 day and extending at least until day three after injury, increased phosphorylation of each of the DLK substrates, MKK4 and MKK7, was evident (Fig. 6b, d, f and Fig. 7). The time course of the activation was slightly different between IHC and immunoblotting, with whole-retina immunoblotting failing to detect the early increase likely because of the scarcity of RGCs in whole-retinal samples. Nonetheless, both 

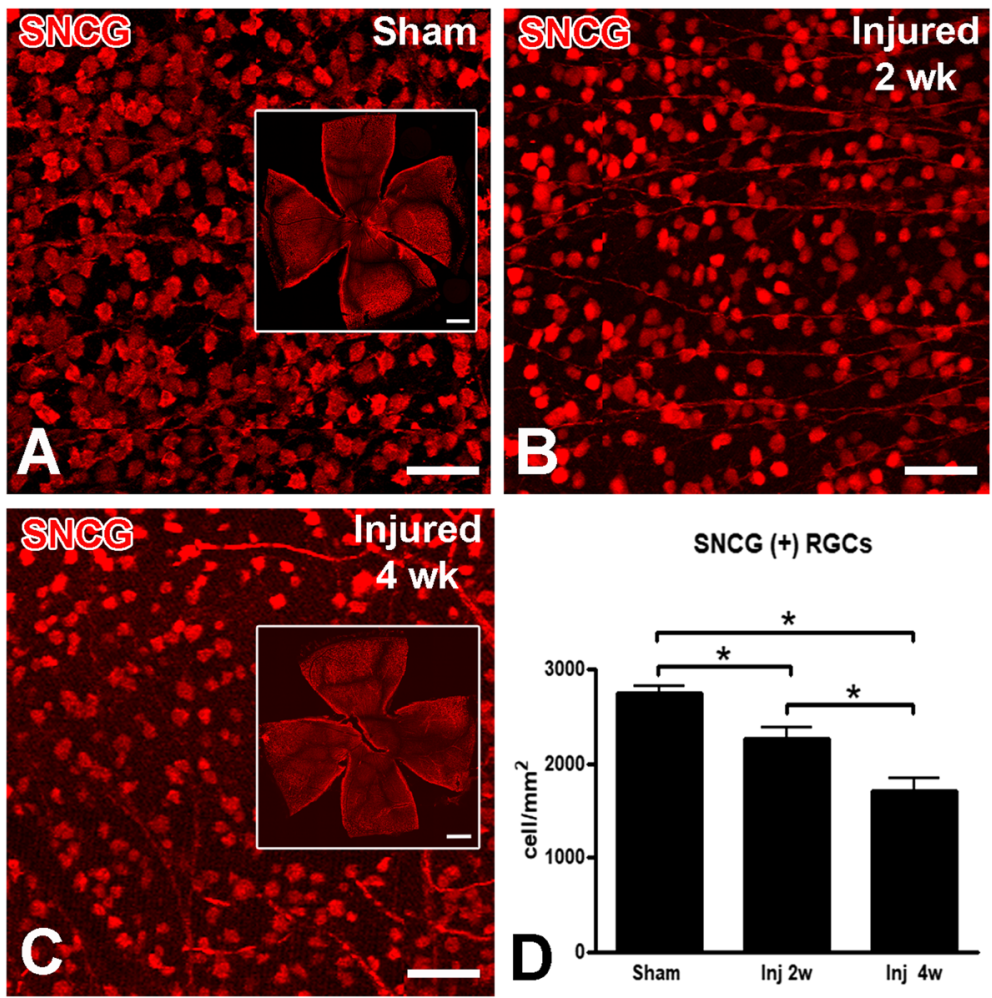

Fig. 5 Progressive RGC loss after IA injury. In these whole-mount retinas stained with the RGC marker $y$-synuclein (SNCG) 2 or 4 weeks after sham (a) or IA injury (b-c), there is evident RGC loss. Insets in a and $\mathbf{c}$ show the retinal flat mounts from which images in main panels originated. Note the progressive decrease in cell density from $\mathbf{a}$ to $\mathbf{c}$. $\mathbf{d}$. A bar graph with densities of surviving SNCG (+) RGCs 2 and 4 weeks post-injury, as compared to sham. Data were analyzed with one-way ANOVA followed by Tukey's post hoc test. ${ }^{*} p<0.05$. Scale bars: a-c, $50 \mu \mathrm{m}$; inserts in a and $\mathbf{c}, 100 \mu \mathrm{m}$

techniques showed a robust activation of JUN after injury that returned to near baseline by 1 week (Fig. 7).

One confounding possibility is that RGCs with active DLK signaling may die, thereby explaining the transient kinase activation. To test this hypothesis, we double stained retinal whole-mounts with antibodies against pJUN for pathway activation and the RGC marker SNCG for viable neurons. The increased density of p-JUNpositive RGCs at one, three, seven, and 14 days after IA injury confirmed activation of the DLK-JNK axis (Fig. 8). Moreover, between one and 14days, there was a decrease in the number of live RGCs with JUN activation, suggesting that kinase activation is transient for most RGCs. Because our TBI model initially activates DLKJNK signaling in $75 \%$ of RGCs (Fig. 8d), but ultimately only $\sim 40 \%$ of RGC somas and axons die (Fig. 5), it is likely that some fraction of RGCs are able to recover from the injury and normalize the DLK signal. Retinal ganglion cells with prolonged p-JUN expression appear atrophic and with decreased SNCG expression, an indication that they may be degenerating neurons. This potential recovery is surprising given that activation of the DLK-JNK pathway in the optic nerve crush model is sustained and leads to death of most RGCs [17]. In contrast, TBI leads to a robust initial activation of the DLKJNK pathway, which is partially reversed in the postacute phase of injury in surviving RGCs.

\section{The activation of JUN in visual TAI is dependent on DLK signaling}

We have previously shown that DLK is the major MAP3K input responsible for JNK activation in response to axotomy in the optic nerve crush model, with additional contribution from LZK $[18,19]$. To explore the degree to which the same kinases are responsible for JNK activation following the nontransecting injury in the IA model, we turned to mice with conditional alleles of $D l k$ and $L z k[18,22]$. Floxed $D l k$ or floxed $D l k / L z k\left(D l k^{f l f l}\right.$ and $D l k^{f l f l} L z k^{f l / f l}$ mice, respectively) were intravitreally injected with AAV-Cre into one eye and a control virus (AAV-GFP) into the fellow eye. After 2 weeks, i.e. time sufficient for AAV to complete its lifecycle and trigger recombination, mice were subjected to TBI with IA. We then measured the rate of JUN phosphorylation as determined by the number of p-JUN (+) RGCs 3 days after injury (when signaling peaks based on immunohistochemical and immunoblot data). Compared to control animals (Fig. 9a), 


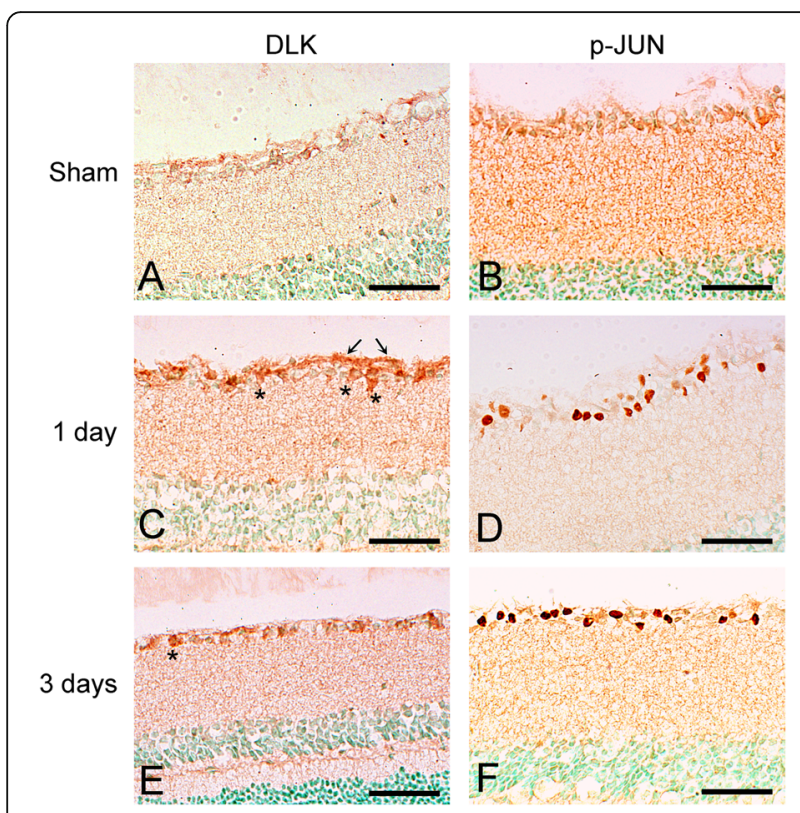

Fig. 6 Activation of the DLK-JNK axis in the retinas of IA-injured mice. $\mathbf{a}, \mathbf{c}, \mathbf{e}$. These horizontal retinal sections were processed for DLK immunohistochemistry and demonstrate the induction of DLK immunoreactivity in cell bodies (asterisks) in the ganglion cell layer and in axons in the nerve fiber layer (arrows) 1 and 3 days postinjury. There is very little immunoreactivity in sham retinas $(\mathbf{a}) . \mathbf{b}, \mathbf{d}, \mathbf{f}$. These sections were immunostained for p-JUN and show the presence of many p-JUN (+) nuclei in the ganglion cell layer 1 and 3 days post-injury. Sham-injured retinas (b) are negative. Scale bars: a-f, $50 \mu \mathrm{m}$

eyes with a targeted disruption of DLK/LZK had a significant ( 75\%) suppression of JUN phosphorylation (Fig. 9c, f). Interestingly, similar suppression was seen with DLK disruption alone (Fig. 9e), suggesting that DLK is a primary mediator of JNK activation in the IA model, and that LZK cannot compensate for a loss of DLK.

\section{Combined deletion of Dlk and Lzk increases survival of RGCs in visual TAI}

To test the role of DLK and LZK in cell death following IA, a separate group of $D l k^{f l f l}$ and $D l k^{f l / f} L z k^{f l / f}$ mice were injected with AAV-Cre or AAV-GFP and RGC survival was quantified 30 days after injury. Deletion of $D l k$ failed to show a significant effect on survival (Fig. 9g). However, combined deletion of $D l k$ and $L z k$ was protective and significantly increased survival of RGCs (Fig. 9b, d, h). These findings suggest that DLK and LZK have redundant abilities to trigger cell death in TAI, which differs from the ONC model in which $D l k$ deletion alone is robustly protective [18].

\section{Pharmacologic DLK/LZK inhibition improves RGC survival in visual TAI}

Since genetic disruption of DLK/LZK protected injured RGCs, we asked whether pharmacological inhibition of
DLK and LZK could similarly improve RGC survival in the IA model. Using published profiling data, we identified the FDA-approved protein kinase inhibitor sunitinib as having activity against DLK and LZK, but not against the downstream kinases MKK4, MKK7 and JNK1-3 [30]. Given that sunitinib penetrates the CNS [31], we tested whether its administration could promote RGC survival in the IA model. First, to confirm target engagement, mice were treated with intraperitoneal sunitinib (or the vehicle control) at 1 day and $4 \mathrm{~h}$ prior to injury, and then once more on the day after injury. Retinas were then harvested and stained for $\mathrm{p}$-JUN. Sunitinib treatment led to a significant decrease in the number of $\mathrm{p}$ JUN positive RGCs, confirming that it was able to partially suppress JNK signaling (Fig. 10). We then repeated the experiment, this time extending the treatment period for 21 days and assaying for RGC survival using SNCG staining of retinal whole-mount preparations. The results show that sunitinib treatment can improve neuronal survival following IA, increasing the number of surviving RGCs from 1500 cells $/ \mathrm{mm}^{2}$ to nearly 2300 cells $/ \mathrm{mm}^{2}$ ( $p<0.05, t$-test) when compared to vehicle, although the effect does not achieve normal (sham) RGC densities (Fig. 10b).

\section{Combined deletion of Dlk and Lzk protects optic nerve} axons early in the course of TAl-associated axonopathy Having established the long-term protective effect of either genetic or pharmacological DLK/LZK inhibition on RGC survival, we explored the role of these kinases in axonal degeneration produced by the IA model. Based on stereological counts of myelinated axons in the optic nerve proximal and distal to the putative site of injury and comparisons between AAV-Cre and control AAVGFP-treated eyes, DLK deletion alone did not appear to protect axons at 3 or 30 days post-injury. The combined deletion of $D l k$ and $L z k$ protected optic nerve axons at 3 days after TBI, but this effect was not sustained at the 30-day time point post injury (Fig. 11). Taken together, these results suggest that TAI-associated axonal degeneration in the visual system is not as dependent on the DLK/LZK genetic program.

\section{Discussion}

Our study explores the role of two MAP3Ks, DLK and LZK, in TAI-associated axonopathy and RGC degeneration in the visual system following IA injury. Traumatic axonal injury in the visual system is featured by axonal transport defects followed by axonal swellings and bulbs in a segment of optic nerve. This is then followed by progressive axonopathic changes (traumatic axonopathy) leading to degeneration of a sizable portion of axons and retrograde death of RGCs. Our findings indicate that TAI in the visual system is associated with the activation 
of the DLK/LZK-JNK axis that is responsible, at least in part, for RGC somal death, although its role in axonal degeneration is limited. The conditional knockout of $D l k$ and $L z k$ in adult mice employed here precludes a neurodevelopmental compensation effect on RGC survival and points to the central role of the DLK-JNK axis in neurodegeneration after TBI. The role of DLK/LZK in triggering RGC degeneration during TAI is further supported by the neuroprotective effect of the FDA-approved kinase inhibitor, sunitinib, a finding with therapeutic potential. Our results show that molecular signals operating in simple forms of axonal injury, i.e. axotomy, play important roles in some of the degenerative outcomes of TAI in the CNS.
We have previously shown that our diffuse model of TBI (IA) leads to multifocal TAI in the corticospinal tract, optic nerve, gracile fasciculus, fornix, and corpus callosum [11, 12]. Traumatic axonal injury in the visual system is associated with optic nerve axonopathy (traumatic axonopathy) that is further characterized here and has been shown to correlate with injury burden [11] The primary biomechanical disruption of the optic nerve corresponds to a region between the orbital apex and the chiasm which is roughly used for the pathological distinctions between "proximal" and "distal" in this paper. Degenerating optic nerve axons show widespread dysmyelination/demyelination that is evident as early as 3 days post-injury. Axonopathy is more severe distal to the site of biomechanical disruption where it continues

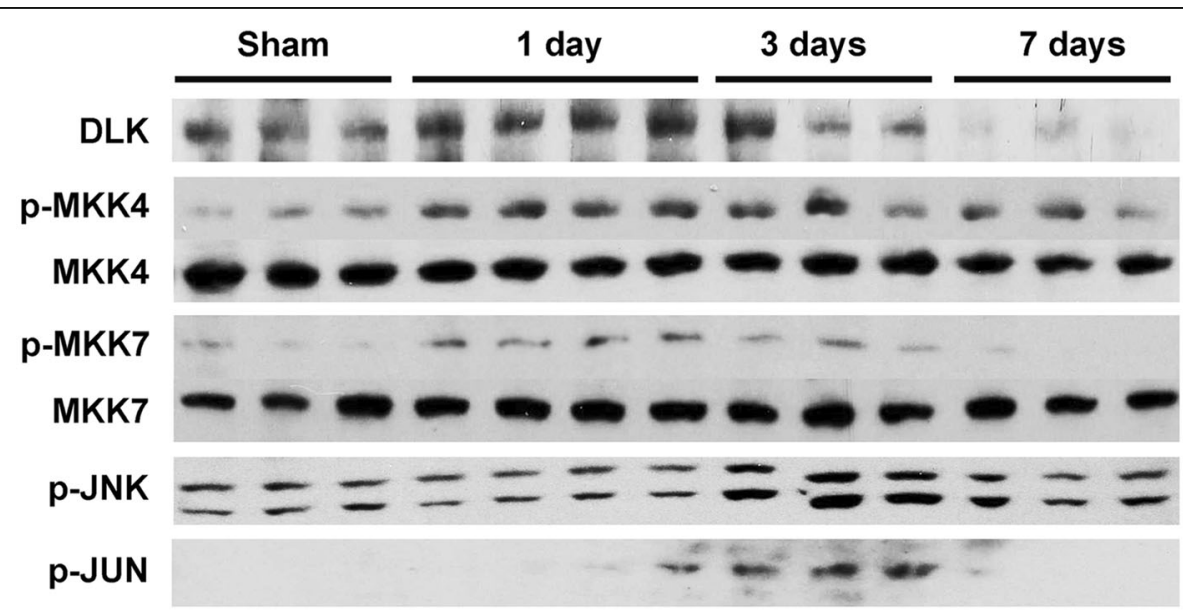

$\beta$-ACTIN

DLK

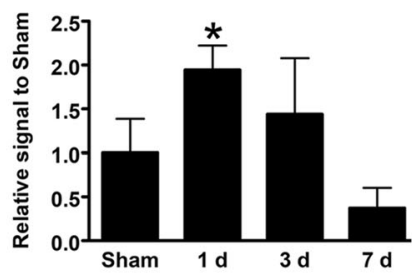

p-JNK

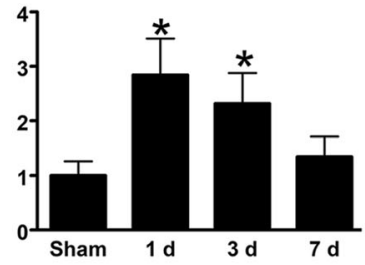

p-MKK4/MKK4

p-MKK7/MKK7
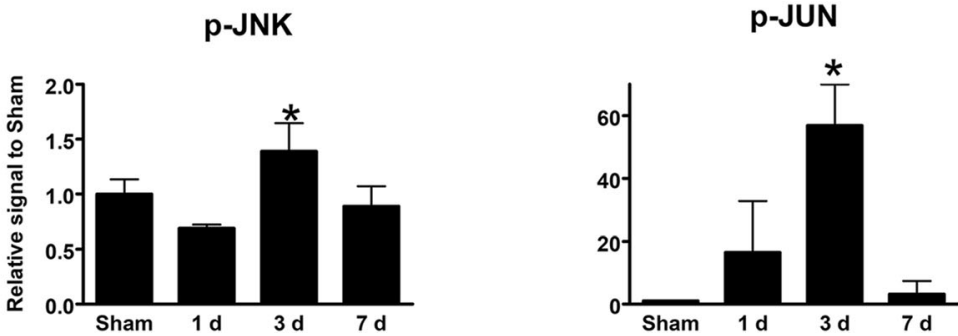

Fig. 7 Expression of kinases in the DLK-JNK pathway in the retina after IA injury by Western blotting. Bar graphs at the bottom represent quantitation of the intensity of protein bands for DLK, activated MKK4 and MKK7 ratios, p-JNK and p-JUN in the sham condition and at 1, 3, and 7 days post-injury. Data were analyzed with one-way ANOVA followed by Tukey's post hoc test. ${ }^{*} p<0.05$ 

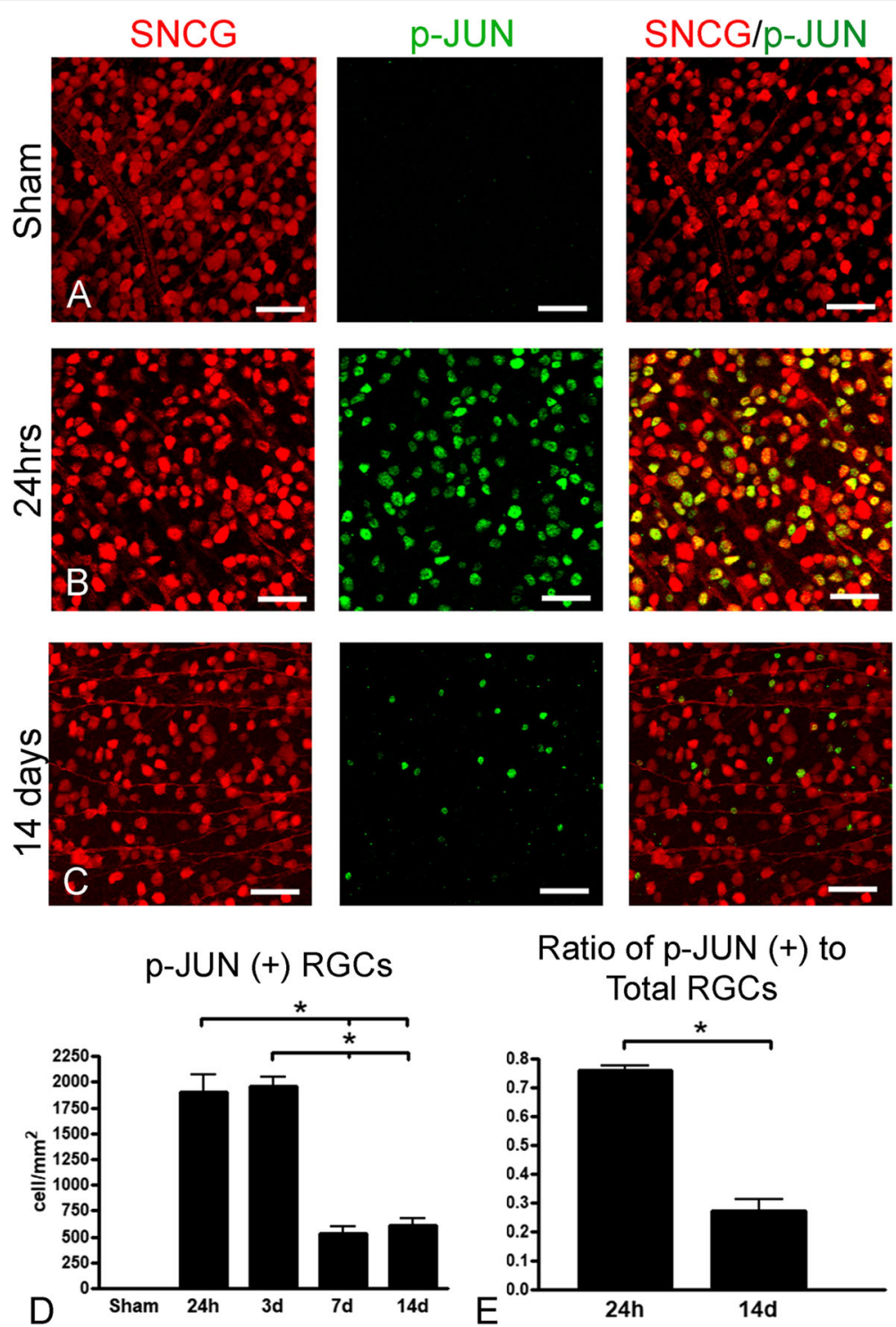

Ratio of p-JUN (+) to
Total RGCs

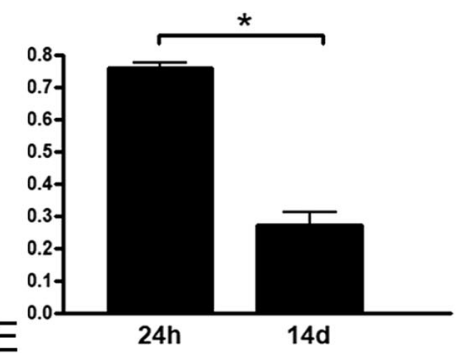

Fig. 8 Quantitative assessment of DLK-JNK activation after IA injury based on counts of p-JUN (+) RGCs. a-c. In whole-mount retinas dually stained for the RGC marker $\gamma$-synuclein (SNCG) (red) and the DLK-JNK marker p-JUN (green), there is induction of p-JUN in RGCS at day 1 (b) and attenuation of labeling by day 14 (c). No p-JUN (+) RGCS are seen in the sham scenario (a). Left-sided images have been acquired with green filter combination for red SNCG immunofluorescence, images at the center have been acquired with blue filter combination for green $p$-JUN immunofluorescence, and panels on the right are merged images in which double-labeled profiles appear orange. Note the extensive colocalization at day 1 , based on the large number of orange profiles (b, right pane). Most p-JUN (+) nuclei at day 14 seem to belong to smaller or atrophic RGCs (c). d-e. Bar graphs of densities of p-JUN (+) RGCs in the retinas of sham and injured animals at 1, 3, 7, and 14 days post-injury (d), and of the ratios of densities of p-JUN (+) RGCs over densities of total RGCs from two representative time points, i.e. 1 and 14 days (e). Significant differences are indicated with asterisks. The comparison in (e) was done to ensure that reduction in numbers of double labeled profiles in (d) was not simply an artifact of the progressive death of RGCs. Data were analyzed with one-way ANOVA followed by Tukey's post hoc test for (d) and with student's t-test for (e). ${ }^{*} p<$ 0.05. Scale bars: $25 \mu \mathrm{m}$

to evolve over the course of the 4-week period examined in our study. Compared to the effects of IA in other CNS tracts, e.g. the corticospinal tract, a distinct feature of TAI in the optic nerve is the retrograde degeneration of neurons (RGCs), in keeping with the classical vulnerability of these nerve cells to death after axonal lesions [32-34]. This notion is further supported by the fact that progression of death of RGC somata appears to lag behind the wave of axonal degeneration. The co-registration of rates of death in RGCs and in proximal axons, both of which are $\sim 25-30 \%$, may suggest a biological correlation between degeneration of perikarya and degeneration of proximal axons. 


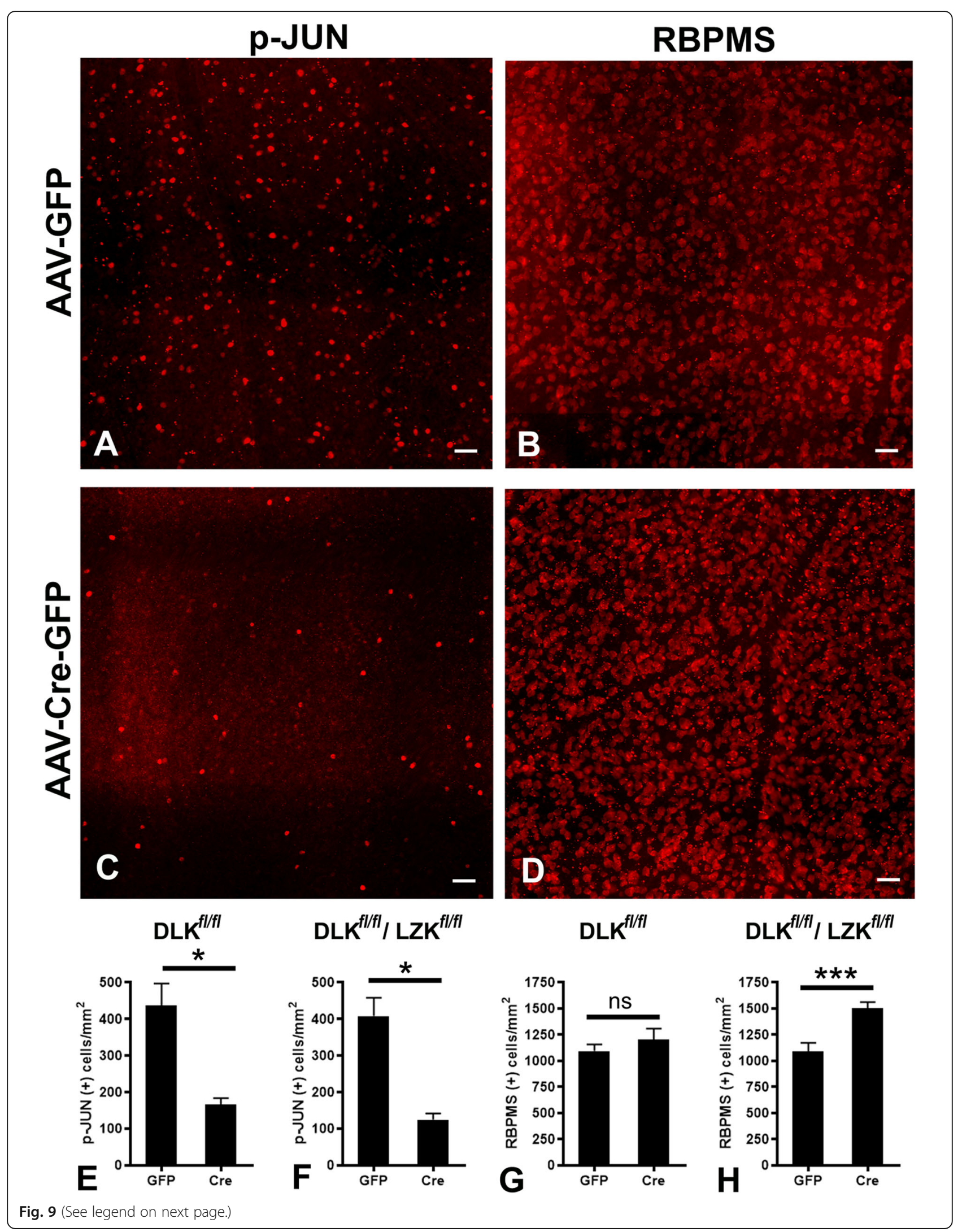


(See figure on previous page.)

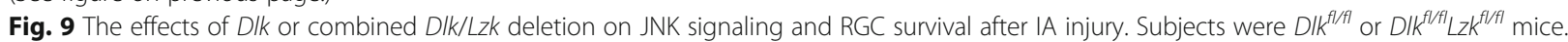
As elsewhere in this paper, p-JUN expression was used as a marker of DLK-JNK activation. Retinal ganglion cells were labeled with RBPMS. a-d. Representative images of p-JUN (a, c) and RBPMS (b, d) immunostained retinas in which Dlk and Lzk was deleted (AAV-Cre-GFP, $\mathbf{c}-\mathbf{d})$ and retinas from fellow eyes in which DIk and Lzk were left intact (AAV-GFP, a-b). Images illustrate the suppression of p-JUN immunoreactivity at day 3 postinjury (c) and improved RGC survival 30 days post-injury (h) with combined DIk/Lzk deletion. e-h. Bar graphs with quantitative assessments of the effects of Dlk or DIk/Lzk deletion on p-JUN expression measured at day 3 after injury (e and $\mathbf{f}$, respectively) and also the effects of DIk or DIk/Lzk deletion on RGC survival measured 30 days after injury ( $\mathbf{g}$ and $\mathbf{h}$, respectively). Scale bars: $\mathbf{a}-\mathbf{d}, 25 \mu \mathrm{m}$

DLK is part of a highly-conserved retrograde injury signal that is triggered by axotomy, leading to the activation of both apoptotic and regenerative processes [17, $19,21,35$ ]. However, simple axotomy models (e.g. optic nerve crush) differ from more clinically relevant models, e.g. TAI, in that the latter tend to produce more graded and incomplete axonal injury. The degree to which DLK is required for TBI- and TAI-associated axonopathy had not been previously explored. Our results suggest some key similarities and differences. As with axotomy, TAI leads to upregulation of DLK and activation of the MKK/JNK/JUN signaling pathway in RGCs. Moreover, DLK acts as obligatory upstream mediator of JUN activation, because targeted disruption of DLK leads to a near-total suppression of JUN phosphorylation. Perhaps the most important difference is that the TAI model triggers DLK activation in such a way that a subset of RGCs can recover and terminate the signal. The mechanism by which this phenomenon occurs is probably related to subthreshold biomechanical injury in a large number of optic nerve axons but may also involve selective vulnerability of subclasses of RGC neurons. These issues need to be explored further because they may have important implications for RGC neuroprotection in the context of TBI.

Furthermore, in contrast to axotomy models in which deletion of $D l k$ by itself rescues the survival of $\sim 75 \%$ of RGCs $[16,17,19]$ in the TAI model, knockout of $D l k$ has little effect on RGC survival. Only when both DLK and LZK were targeted did we see an increase in RGC survival, suggesting a degree of genetic redundancy for these two highly-related kinases. Not surprisingly, the degree of redundancy seems to be dependent on the model, with the TAI model and primary RGC cultures showing a large degree of DLK/LZK redundancy (i.e. combined inhibition is required for robust survival), while the ONC model shows a lesser degree of redundancy (i.e. combined disruption produces a more modest increase in survival over $D l k$ disruption alone). It is also interesting to note that deletion of $D l k$ with or without Lzk leads to a significant reduction in the downstream phosphorylation of JUN but only the combined deletion of the two protects RGC viability. Although we cannot exclude effects on the kinetics or localization of JNK activation, these data could indicate that LZK may be upstream of an as-yet-unidentified pathway responsible for RGC cell death in TAI.

In order to develop an expedited route to clinically evaluate DLK/LZK inhibition as a neuroprotective strategy, we previously surveyed FDA-approved protein kinase inhibitors for ones with activity against DLK and LZK. This approach identified sunitinib $\left(\right.$ Sutent $\left.^{\circledR}\right)$, FDA-

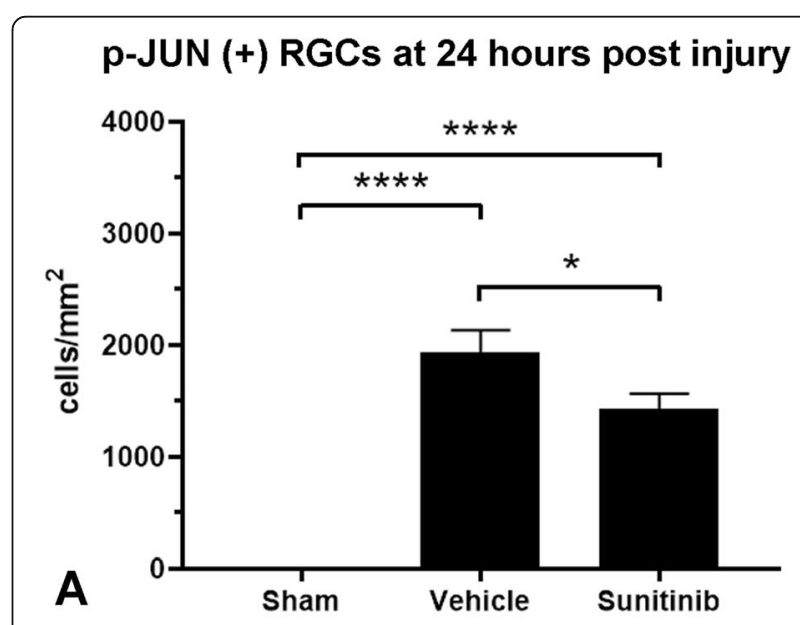

\section{SNCG (+) RGCs at 3 weeks post injury}

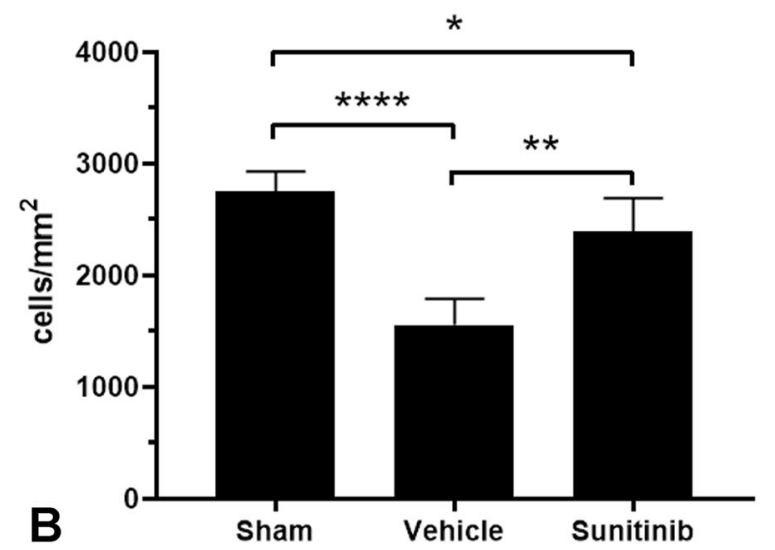

Fig. 10 Suppression of JNK signaling and promotion of RGC survival by sunitinib in the IA model. a As elsewhere in this paper, DLK-JNK activation in retina was marked by density of p-JUN immunoreactivity in retinal flatmounts that here was measured at day 1 post injury. b Survival was based on the density of SNCG $(+)$ cells that was measured 3 weeks post injury. Data were analyzed with one-way ANOVA followed by Tukey's post hoc test. ${ }^{*} p<0.05,{ }^{* *} p<0.01,{ }^{* *} p<0.001$ 


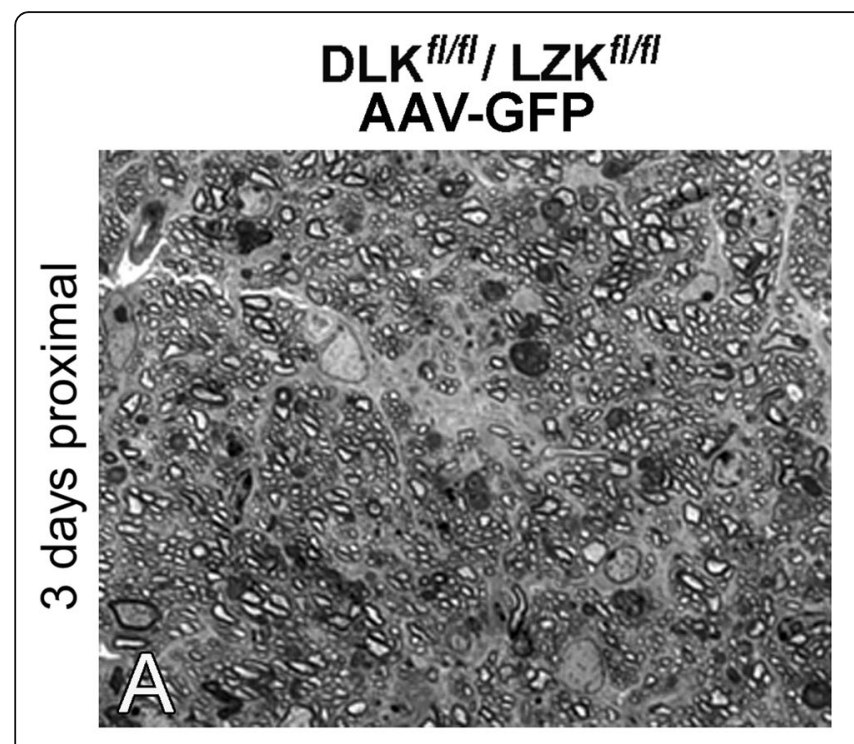

proximal
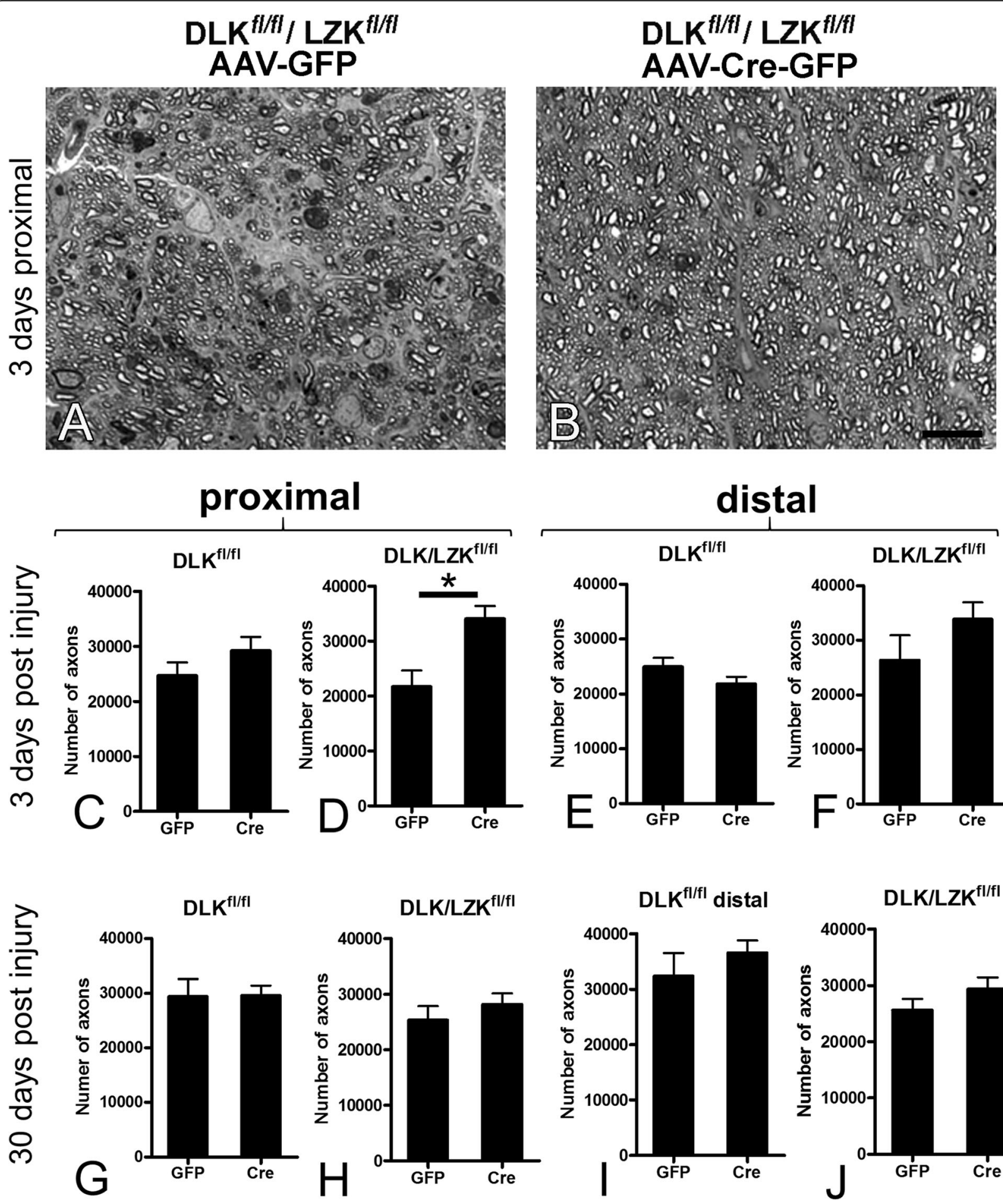

\section{distal}
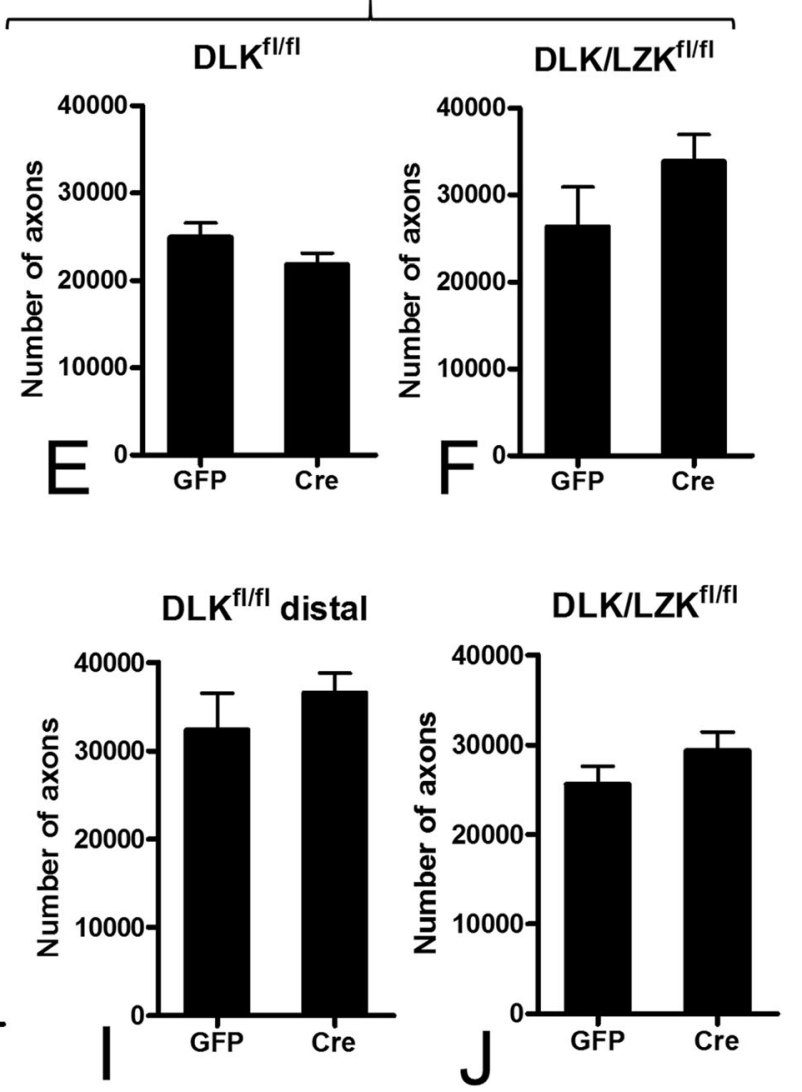

Fig. 11 Combined DIk/Lzk deletion using $D / k^{f l / f l} L z k^{f l / f l}$ mice delays axonal degeneration in the optic nerve. a-b. Representative images from semithin sections of the proximal optic nerve 3 days post injury showing the protective effect of D/k/Lzk deletion. Cre-treated optic nerve is depicted on the right (b) and control optic nerve from the fellow eye is shown on the left (a). c-j. Bar graphs with counts of axons in the optic nerve proximal (c-d and $\mathbf{g}-\mathbf{h})$ and distal $(\mathbf{e}-\mathbf{f}$ and $\mathbf{i}-\mathbf{j})$ to the site of the initial traumatic disruption three (c-f) and 30 ( $\mathbf{g}$-j) days post injury in D/kflfl $(\mathbf{c}, \mathbf{e}, \mathbf{g}, \mathbf{i})$ or $D / K^{f l / f l} L z K^{f l / f l}(\mathbf{d}, \mathbf{f}, \mathbf{h}, \mathbf{j})$ mice treated with Cre or control (GFP) vectors in the two eyes. There are eight combinations of genotype $\times$ proximal or distal location $\times$ early or late time point post injury. Of all combinations, the only significant effect on axonal degeneration is that of the deletion of both Dlk and Lzk in the proximal nerve early post injury $(\mathbf{d})$. Data were analyzed with student's t-test. * $p<0.05$. Scale bars: a-b, $25 \mu \mathrm{m}$ 
approved for renal cell carcinoma and gastrointestinal stromal tumor, as having high nanomolar $\mathrm{IC}_{50}$ for both DLK and LZK. Moreover, we showed that sunitinib increased the survival of induced pluripotent stem cell (iPSC)-derived human RGCs [18]. Here we have extended these findings to demonstrate that pharmacological blockade of DLK and LZK with sunitinib increases RGC survival in vivo in a rodent TBI model. To these authors' knowledge, and with the possible exception of antioxidants [36], this is the first demonstration of an FDA-approved compound decreasing neuronal cell death in a TBI model.

Central nervous system tracts other than the visual system that are vulnerable to TAI and succumb to traumatic axonopathy [12] may also use DLK-dependent injury signals; therefore, our findings raise the prospect of using protein kinase inhibitors as part of a neuroprotective strategy for TBI. Traumatic brain injury very commonly affects axons and the state of axons after injury is important for the integrity of neuronal circuitry and the function of neural networks [37]. After we established that RGC somatic death is, at least in part, a DLK/LZKdependent phenomenon, we explored the effect of the DLK/LZK pathway on axonal survival. DLK appears to be implicated in axonal degeneration through a negative effect on levels of SCG10, an anterogradely transported protein that promotes axonal survival after axotomy in vitro [38]. More recently, the involvement of DLK in axonal degeneration has been examined in vitro using primary dorsal root ganglion neurons [23]. These experiments have revealed an important role of DLK in maintaining basal levels of NMNAT2, an essential axonal survival factor, through the degradation of the palmitoylated form of the enzyme under normal conditions. Deletion of $D l k$ raises basal level of anterogradely transported NMNAT2 prior to injury, and thus delays axonal degeneration. This protective effect is more pronounced when combined with deletion of the Phrl/ Skp1a/Fbxo45 ligase complex that is important for the degradation of the nonpalmitoylated fraction of NMNAT2 [23]. Consistent with these observations, we found that the combined deletion of $D l k$ and $L z k$ only protected optic nerve axons from degeneration early, i.e. 3 days, post injury. To our knowledge, this is the first demonstration that LZK plays a role, albeit limited, in an active axonal degeneration program. This finding is in line with the kinetics of NMNAT2, a labile protein that needs continuous replenishment to exert protective effects on axons [39]. The blockade of anterograde transport that occurs with TAI would have prevented the axonal transport of NMNAT2, leaving the axon only with basal levels of the protein, which may be higher is neurons with deleted $D l k / L z k$. This effect, however, may not be sufficient to completely protect injured axons, as suggested by the fact that there is no significant effect on survival at 30 days post injury.

\section{Conclusion}

Here we have shown the RGC loss after TBI can be prevented, at least in part, by the genetic deletion or pharmacological inhibition of DLK/LZK. This finding may be an important step in protecting RGCs in the context of TBI and potentially allowing them to reintegrate into the visual circuitry if many axons are still relatively intact or if regenerative strategies become more effective in the future [40]. We also showed that by blocking DLK/LZK we may delay degeneration of RGC axons although, as has been also shown in simple axotomy lesions, the effect on RGC somata is clearly more robust [16, 41-43]. Finally, here we showed that an FDA-approved drug, sunitinib, with activity against both DLK and LZK, is able to increase RGC survival in a TBI model. Although future work will need to establish if pharmacologic DLK/LZK inhibition can prevent degeneration when given in a more clinically-relevant postinjury paradigm, our findings already suggest that this intervention may be a promising lead for translational efforts in the field of TBI.

\begin{abstract}
Abbreviations
APP: Amyloid precursor protein; BBB: Blood brain barrier; CTB: Cholera toxin B; DAB: 3,3'-diaminobenzidine; DAPI: 4', 6-diamidino-2-phenylindole;

DLK: Dual leucine zipper kinase (MAP3K12); IA: Impact acceleration; IHC: Immunohistochemistry; JNK: JUN N-terminal kinase; LZK: Leucine zipper kinase (MAP3K13); MAP2K: Mitogen activated protein kinase kinase; MAP3K: Mitogen activated protein kinase kinase kinase; MAPK: Mitogen activated protein kinase; MKK4: Mitogen activated protein kinase kinase four; MKK7: Mitogen activated protein kinase kinase seven; NMNAT2: Nicotinamide mononucleotide adenylyl transferase two; ON: Optic nerve; ONC: Optic nerve crush; OT: Optic tract; p-JUN: phosphorylated JUN; RBPMS: RNA binding protein, mRNA processing factor; RGC: Retinal ganglion cell; SC: Superior colliculus; siRNA: small interfering RNA; SNCG: Gamma synuclein;

TAl: Traumatic axonal injury; TBI: Traumatic brain injury
\end{abstract}

\section{Acknowledgements}

We thank Santiago Gonzalez for expert technical assistance.

\section{Authors' contributions}

DSW, DJZ and VEK were responsible for the design, analysis and interpretation of all experiments and were major contributors to the writing of the manuscript. NKZ played a major role in the design, performance, analysis and interpretation of many experiments and the writing of the manuscript. ASA, LX, BJK, YG, NS, AKP and ML were involved in the TBl experiments, immunohistochemistry and cell and axonal counts. JR assisted with $\mathrm{HC}$ and was responsible for immunoblotting and preparation of figures. All authors read and approved the final manuscript.

\section{Authors' information}

Not applicable.

\section{Funding}

D.S.W. received funding from the Ziegler Career Development Award, Research to Prevent Blindness Career Development Award, DoD Vision Research Program Translational Research Award and NEI R01EY029342-01. D.J.Z. received funding from NIH (including core grant 5P30EY001765), Research to Prevent Blindness, BrightFocus Foundation, the Department of Defense, and the Guerrieri Family Foundation. V.E.K received funding from the Department of Defense W81XWH-14-0396, State of Maryland TEDCO 2015-MSCRFI-1718, National Institutes of Health RO1EY028039, the Sidran 
Family Foundation, and the Spyros N. Lemos Memorial Fund. In all cases, the funding agencies were not involved in the acquisition, analysis, interpretation and/or presentation/reporting of data.

\section{Availability of data and materials}

The primary data used and/or analysed during the current study (e.g. images of the original immunoblots) are available from the corresponding author on reasonable request.

\section{Ethics approval and consent to participate}

All animal experiments were carried out in accordance with the ARVO Statement for the Use of Animals in Ophthalmic and Vision Research.

\section{Consent for publication}

Not applicable.

\section{Competing interests}

The authors declare that they have no competing interests.

\section{Author details}

'Department of Ophthalmology, University of California, San Diego, La Jolla 92037, USA. ${ }^{2}$ Department of Neurology, The Johns Hopkins University School of Medicine, Baltimore, MD 21205, USA. ${ }^{3}$ Division of Neuropathology, Department of Pathology, The Johns Hopkins University School of Medicine, Baltimore, MD 21205, USA. ${ }^{4}$ Department of Ophthalmology, The Johns Hopkins University School of Medicine, Baltimore, MD 21205, USA. ${ }^{5}$ Department of Otolaryngology-Head and Neck Surgery, The Johns Hopkins University School of Medicine, Baltimore, MD 21205, USA. ${ }^{6}$ Department of Molecular Biology and Genetics, The Johns Hopkins University School of Medicine, Baltimore, MD 21205, USA. 7 The Solomon H. Snyder Department of Neuroscienc, The Johns Hopkins University School of Medicine, Baltimore, MD 21205, USA. ${ }^{8}$ Institute of Genetic Medicine, The Johns Hopkins University School of Medicine, Baltimore, MD 21205, USA. ${ }^{9}$ Department of Psychiatry and Behavioral Sciences, The Johns Hopkins University School of Medicine, Baltimore, MD 21205, USA.

\section{Received: 22 July 2019 Accepted: 8 November 2019} Published online: 27 November 2019

\section{References}

1. Frieden TR, Houry D, Baldwin G. CDC Report Congress on traumatic brain injury in the United States: Epidemiology and Rehabilitation, vol. 2015; 2015.

2. Adams JH, Murray MF. Atlas of post-mortem techniques in neuropathology, vol. 1982. Cambridge: Cambridge University Press; 1982.

3. Blumbergs PC, Jones NR, North JB. Diffuse axonal injury in head trauma. J Neurol Neurosurg Psychiatry. 1989;52:838-41.

4. Blumbergs PC, Scott G, Manavis J, Wainwright H, Simpson DA, Mclean AJ. Staining of amyloid precursor protein to study axonal damage in mild head-injury. Lancet. 1994;344(8929):1055-6.

5. Mittl RL, Grossman RI, Hiehle JF, Hurst RW, Kauder DR, Gennarelli TA, et al. Prevalence of MR evidence of diffuse axonal injury in patients with mild head injury and normal head CT findings. AJNR Am J Neuroradiol. 1994; 15(8):1583-9.

6. Strich SJ. Diffuse degeneration of the cerebral white matter in severe dementia following head injury. J Neurol Neurosurg Psychiatry. 1956;19: 163-85

7. Foda MAA, Marmarou A. A New Model of Diffuse Brain Injury in Rats .2. Morphological Characterization. J Neurosurg. 1994;80(2):301-13.

8. Marmarou A, Foda MAA, Vandenbrink W, Campbell J, Kita H, Demetriadou K. A New Model of Diffuse Brain Injury in Rats .1. Pathophysiology and Biomechanics. J Neurosurg. 1994;80(2):291-300.

9. Povlishock JT, Erb DE, Astruc J. Axonal response to traumatic brain injury: reactive axonal change, deafferentation, and neuroplasticity. J Neurotrauma. 1992;9(Suppl. 1):S189-200.

10. Povlishock JT, Marmarou A, McIntosh T, Trojanowski JQ, Moroi J. Impact acceleration injury in the rat: evidence for focal axolemmal change and related neurofilament sidearm alteration. J Neuropathol Exp Neurol. 1997; 56(4):347-59.

11. Xu L, Nguyen JV, Lehar M, Menon A, Rha E, Arena J, et al. Repetitive mild traumatic brain injury with impact acceleration in the mouse: multifocal axonopathy, neuroinflammation, and neurodegeneration in the visual system. Exp Neurol. 2016;275(Pt 3):436-49.

12. Ziogas NK, Koliatsos VE. Primary traumatic Axonopathy in mice subjected to impact acceleration: a reappraisal of pathology and mechanisms with highresolution anatomical methods. J Neurosci. 2018;38(16):4031-47.

13. Bricker-Anthony C, Rex TS. Neurodegeneration and vision loss after mild blunt trauma in the C57BI/6 and DBA/2J mouse. PLoS One. 2015;10(7): e0131921.

14. Koliatsos VE, Cernak I, Xu L, Song Y, Savonenko A, Crain BJ, et al. A mouse model of blast injury to brain: initial pathological, neuropathological, and behavioral characterization. J Neuropathol Exp Neurol. 2011;70(5):399-416.

15. Wang J, Hamm RJ, Povlishock JT. Traumatic axonal injury in the optic nerve: evidence for axonal swelling, disconnection, dieback, and reorganization. J Neurotrauma. 2011;28(7):1185-98.

16. Fernandes KA, Harder JM, John SW, Shrager P, Libby RT. DLK-dependent signaling is important for somal but not axonal degeneration of retinal ganglion cells following axonal injury. Neurobiol Dis. 2014;69:108-16.

17. Watkins TA, Wang B, Huntwork-Rodriguez S, Yang J, Jiang Z, EasthamAnderson J, et al. DLK initiates a transcriptional program that couples apoptotic and regenerative responses to axonal injury. Proc Natl Acad Sci U S A. 2013;110(10):4039-44.

18. Welsbie DS, Mitchell KL, Jaskula-Ranga V, Sluch VM, Yang Z, Kim J, et al. Enhanced functional genomic screening identifies novel mediators of dual Leucine zipper kinase-dependent injury signaling in neurons. Neuron. 2017; 94(6):1142-54.

19. Welsbie DS, Yang Z, Ge Y, Mitchell KL, Zhou X, Martin SE, et al. Functional genomic screening identifies dual leucine zipper kinase as a key mediator of retinal ganglion cell death. Proc Natl Acad Sci U S A. 2013;110(10):4045-50.

20. Holland SM, Collura KM, Ketschek A, Noma K, Ferguson TA, Jin Y, et al. Palmitoylation controls DLK localization, interactions and activity to ensure effective axonal injury signaling. Proc Natl Acad Sci U S A. 2016;113(3):763-8.

21. Xiong X, Wang X, Ewanek R, Bhat P, DiAntonio A, Collins CA. Protein turnover of the Wallenda/DLK kinase regulates a retrograde response to axonal injury. J Cell Biol. 2010;191(1):211-23.

22. Miller BR, Press C, Daniels RW, Sasaki Y, Milbrandt J, DiAntonio A. A dual leucine kinase-dependent axon self-destruction program promotes Wallerian degeneration. Nat Neurosci. 2009;12(4):387-9.

23. Summers DW, Milbrandt J, DiAntonio A. Palmitoylation enables MAPKdependent proteostasis of axon survival factors. Proc Natl Acad Sci U S A. 2018;115(37):E8746-E54.

24. Yang J, Wu Z, Renier N, Simon DJ, Uryu K, Park DS, et al. Pathological axonal death through a MAPK cascade that triggers a local energy deficit. Cell. 2015;160(1-2):161-76

25. Arevalo MA, Azcoitia I, Garcia-Segura LM. The neuroprotective actions of oestradiol and oestrogen receptors. Nat Rev Neurosci. 2015;16(1):17-29.

26. Green PS, Simpkins JW. Neuroprotective effects of estrogens: potential mechanisms of action. Int J Dev Neurosci. 2000;18(4-5):347-58.

27. Mollayeva T, Mollayeva S, Colantonio A. Traumatic brain injury: sex, gender and intersecting vulnerabilities. Nat Rev Neurol. 2018;14(12):711-22.

28. Raghava N, Das BC, Ray SK. Neuroprotective effects of estrogen in CNS injuries: insights from animal models. Neurosci Neuroecon. 2017;6:15-29.

29. Suzuki S, Brown CM, Wise PM. Mechanisms of neuroprotection by estrogen. Endocrine. 2006;29(2):209-15.

30. Karaman MW, Herrgard S, Treiber DK, Gallant P, Atteridge CE, Campbell BT, et al. A quantitative analysis of kinase inhibitor selectivity. Nat Biotechnol. 2008;26(1):127-32.

31. Tang SC, Lagas JS, Lankheet NA, Poller B, Hillebrand MJ, Rosing H, et al. Brain accumulation of sunitinib is restricted by P-glycoprotein (ABCB1) and breast cancer resistance protein (ABCG2) and can be enhanced by oral elacridar and sunitinib coadministration. Int J Cancer. 2012;130(1):223-33.

32. Levkovitch-Verbin H. Animal models of optic nerve diseases. Eye (Lond). 2004;18(11):1066-74.

33. Lobato RD. Historical vignette of Cajal's work "degeneration and regeneration of the nervous system" with a reflection of the author. Neurocirugia (Astur). 2008;19(5):456-68.

34. Villegas-Perez MP, Vidal-Sanz M, Rasminsky M, Bray GM, Aguayo AJ. Rapid and protracted phases of retinal ganglion cell loss follow axotomy in the optic nerve of adult rats. J Neurobiol. 1993;24(1):23-36.

35. Ghosh AS, Wang B, Pozniak CD, Chen M, Watts RJ, Lewcock JW. DLK induces developmental neuronal degeneration via selective regulation of proapoptotic JNK activity. J Cell Biol. 2011;194(5):751-64. 
36. Shen Q, Hiebert JB, Hartwell J, Thimmesch AR, Pierce JD. Systematic review of traumatic brain injury and the impact of antioxidant therapy on clinical outcomes. Worldviews Evid-Based Nurs. 2016;13(5):380-9.

37. Buki A, Povlishock JT. All roads lead to disconnection? Traumatic axonal injury revisited. Acta Neurochir. 2006;148(2):181-93.

38. Shin JE, Miller BR, Babetto E, Cho Y, Sasaki Y, Qayum S, et al. SCG10 is a JNK target in the axonal degeneration pathway. Proc Natl Acad Sci U S A. 2012; 109(52):E3696-705.

39. Gilley J, Coleman MP. Endogenous Nmnat2 is an essential survival factor for maintenance of healthy axons. PLoS Biol. 2010;8(1):e1000300.

40. Lim JH, Stafford BK, Nguyen PL, Lien BV, Wang C, Zukor K, et al. Neural activity promotes long-distance, target-specific regeneration of adult retinal axons. Nat Neurosci. 2016;19(8):1073-84.

41. Jakobs TC, Libby RT, Ben Y, John SW, Masland RH. Retinal ganglion cell degeneration is topological but not cell type specific in DBA/2J mice. J Cell Biol. 2005;171(2):313-25.

42. Libby RT, Li Y, Savinova OV, Barter J, Smith RS, Nickells RW, et al. Susceptibility to neurodegeneration in a glaucoma is modified by Bax gene dosage. PLoS Genet. 2005;1 (1):17-26.

43. Whitmore AV, Libby RT, John SW. Glaucoma: thinking in new ways-a role for autonomous axonal self-destruction and other compartmentalised processes? Prog Retin Eye Res. 2005;24(6):639-62.

\section{Publisher's Note}

Springer Nature remains neutral with regard to jurisdictional claims in published maps and institutional affiliations.

Ready to submit your research? Choose BMC and benefit from:

- fast, convenient online submission

- thorough peer review by experienced researchers in your field

- rapid publication on acceptance

- support for research data, including large and complex data types

- gold Open Access which fosters wider collaboration and increased citations

- maximum visibility for your research: over $100 \mathrm{M}$ website views per year

At BMC, research is always in progress.

Learn more biomedcentral.com/submissions 